This PDF is a selection from a published volume from the National Bureau of Economic Research

Volume Title: Social Security Programs and Retirement around the World: The Relationship to Youth Employment

Volume Author/Editor: Jonathan Gruber and David A. Wise, editors

Volume Publisher: University of Chicago Press

Volume ISBN: 978-0-226-30948-4; 0-226-30948-7

Volume URL: http://www.nber.org/books/grub08-1

Conference Date:

Publication Date: February 2010

Chapter Title: Youth Unemployment and Retirement of the Elderly: The Case of Italy Chapter Author: Agar Brugiavini, Franco Peracchi

Chapter URL: http://www.nber.org/chapters/c8256

Chapter pages in book: (167 - 215) 


\section{Youth Unemployment and Retirement of the Elderly The Case of Italy}

Agar Brugiavini and Franco Peracchi

\subsection{Introduction}

The dramatic increase in life expectancy at older ages and the trend toward earlier withdrawal from the labor force are changing the age composition of the labor force in many European countries, but especially in Italy. The Lisbon declaration (2000) by the European Union (EU) has emphasized the importance of increasing labor supply by setting an ambitious target participation rate of 70 percent for the working-age population. Besides women, the segments of the Italian population that are furthest away from this target are the youth and the elderly. As for the elderly, the financial incentives of the Italian social security system have encouraged retirement at relatively young ages throughout the 1980s and most of the 1990s (Brugiavini and Peracchi 2003, 2007), and only recently have these trends shown some sign of reversal.

We have shown in previous work (Brugiavini and Peracchi 2007) that the welfare gains of the elderly are large both in absolute and in relative terms; that is, relative to other demographic groups, particularly the young. The issue that we address in this chapter is whether early exit prompted reductions in the youth unemployment rate, as is often claimed by union leaders, thus partly compensating for the welfare redistribution operated in favor of the elderly. This question necessarily relates to the labor market policies enacted during the last decades and the impact that these had on the participation rate of younger workers. The aim of this chapter is to analyze

Agar Brugiavini is professor of economics at the University Ca' Foscari of Venice and a research associate of the IFS and SSAV. Franco Peracchi is professor of econometrics at the University of Rome "Tor Vergata." 
the interaction of these policies and the social security legislation in shaping the age profile of the labor market and the trends in labor force participation.

\subsection{Unemployment Trends in Italy}

The Italian labor market is characterized by relatively high unemployment rates, particularly for the young. The two main characteristics of the youth unemployment rate in Italy are (a) an extraordinary regional variability and (b) a high percentage of first-job seekers among the unemployed young, particularly in the southern regions.

Figure 6.1 shows the trend in unemployment rates of young people (aged twenty to twenty-four) between 1977 and 2004, both in aggregate terms and separately for males and females. The vertical bars indicate the years of the main reforms in the social security system. The youth unemployment rate shows a clear upward trend with a strong cyclical component and reaches a first peak of 28.6 percent in 1987 and a second peak of 32.5 percent in 1998. It is clear that Italy is a country with a serious youth unemployment problem.

The large variability across regions is documented in figure 6.2 , which distinguishes five regions: northeast (NE), northwest (NW), center (C), southeast (SE), and southwest (SW). While in the southern regions, the unemployment rate for the age group twenty to twenty-four can be as high

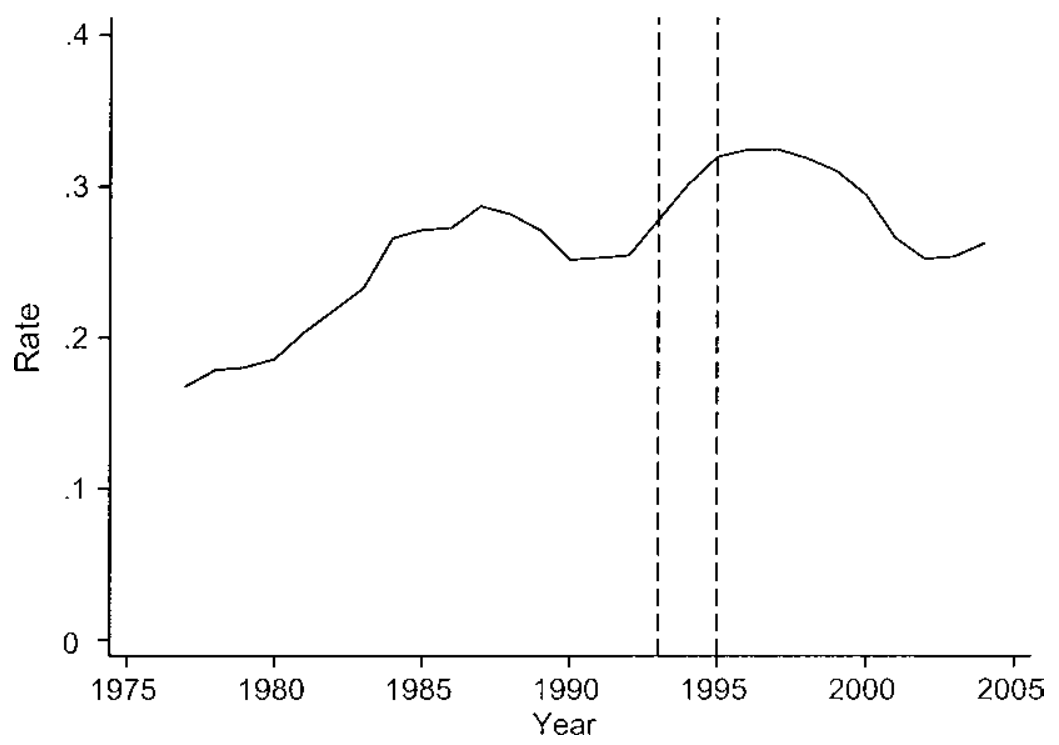

Fig. 6.1 Trends in youth unemployment rate 


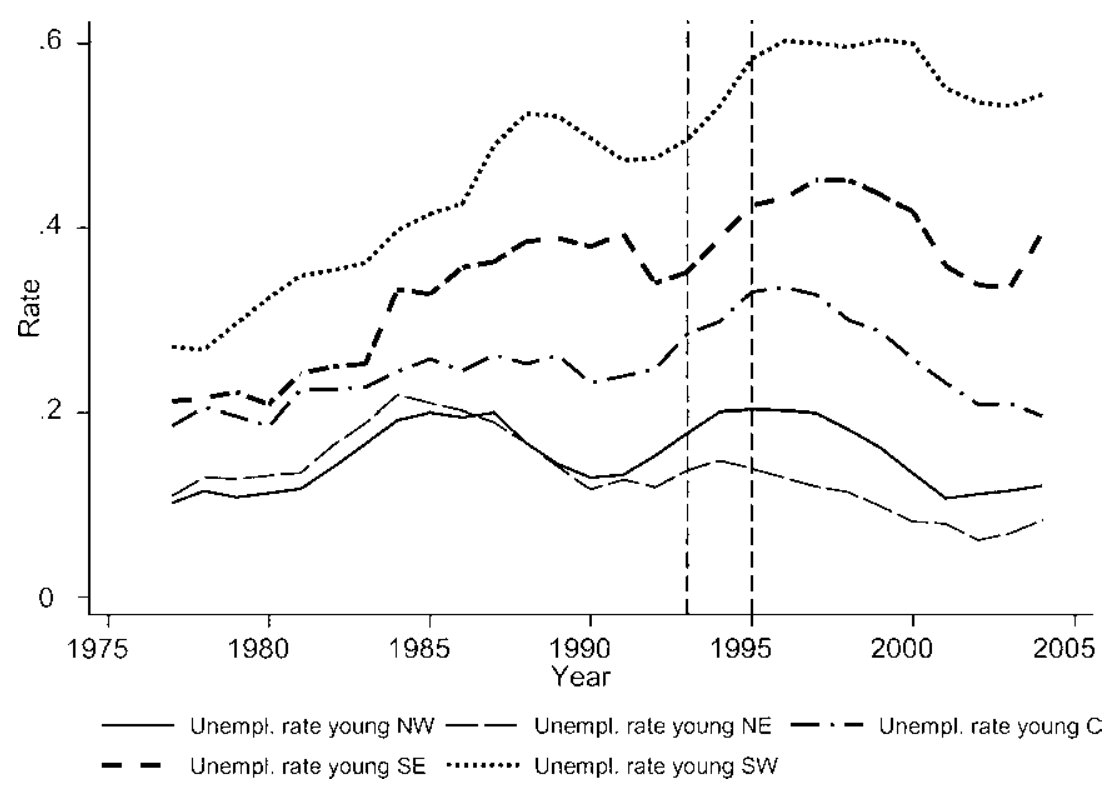

Fig. 6.2 Trends in the regional youth unemployment rate

as 50 percent, northern regions witness youth unemployment rates below 20 percent, and for the regions in the northeast, even below 10 percent.

Several explanations have been put forward to interpret these figures. One strand of the literature looks at the issue of labor mismatch. In particular, some authors have explored the hypothesis that the unbalanced evolution of labor demand and supply across different geographical areas (i.e., regional mismatch) is partly responsible for the increase in aggregate and youth unemployment, particularly in the southern regions. ${ }^{1}$ According to this view, the determinants of the regional unemployment differential can be seen in the following elements: employment performance in the south has worsened in the presence of a sustained labor force growth; labor force mobility from the south to the northern and central areas has sensibly declined with the reduction of earnings differentials and with the increase in social transfers per head; and real wages in the south are not affected by local unemployment conditions but depend on the unemployment rate prevailing in the leading areas - that is, northern regions (Brunello, Lupi, and Ordine 2001). In other words, despite the increasing unemployment in the south, labor mobility from the south to the north has been low, and relative wages have not adjusted to reflect worsened local labor market conditions. 
Together with the regional mismatch and the lack of geographical mobility, the skill mismatch also plays a role in determining high youth unemployment rates in Italy. Some authors (see, for example, Caroleo [1999]) stress the fact that despite the higher educational attainments of the new entrants into the labor market, the educational mix does not match well to the trends in labor demand.

Figure 6.3 shows the time trend in the percentage of people with high school diplomas and university degrees among people aged twenty to twenty-nine. This percentage has increased sharply over the last thirty years. The percentage of people with high school degrees has nearly doubled, from less than 30 percent in 1977 to almost 60 percent in 2004. During the same period, the percentage of people with university degrees has increased by nearly three times, from about 7 percent to almost 20 percent. The increase in the educational attainments of the younger cohorts implies a delayed entry into the labor market (Contini 2005). It also gives rise to problems of mismatch between skills supplied and skills demanded. The relevance of these problems differs across regions (Caroleo and Mazzotta 1999). In the southern regions, the mismatch between skills supplied - often generic and of low qualification - and skills demanded is just one of the explanations of youth unemployment. On the other hand, in the northern and central regions, skill mismatch seems to represent the main problem. In this case, employers ask for specialized manual workers, whereas young suppliers offer a medium-high, but generic, educational level.

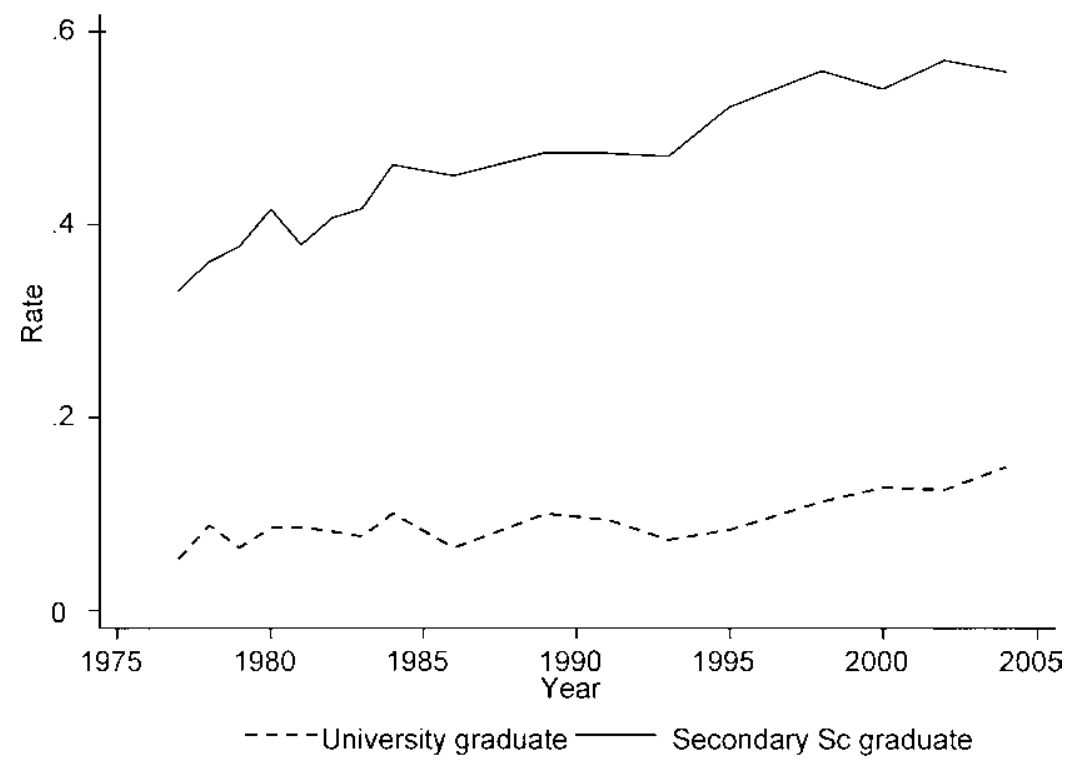

Fig. 6.3 Trend of educational attainments: Rate of high school diploma and university degrees, workers age 20 to 29 
Another element that has been often considered in explaining the high level of youth unemployment in Italy is the high reservation wage of the young, particularly in the south. This high reservation wage-combined with the fact that particularly in the south, the majority of the unemployed young are first-job seekers - is surely a relevant determinant of the high youth unemployment. It is generally agreed that the absence of welfare support for first-job seekers (i.e., the absence of minimum income provisions and unemployment benefits) and the strengthening of the role of the family have contributed to increasing the level of the reservation wage of young job seekers. Moreover, particularly in the south, the public sector has represented for a long time the only access to a "regular" job, and young people have built their own human capital and their own aspirations on this type of job. Consequently, their reservation wage is built on the level of wages in the public sector (Caroleo and Mazzotta 1999).

The existence of a legal minimum wage is usually regarded as a barrier to the recruitment of young workers. The situation in Italy represents somewhat of a paradox. In fact, Italy has no legal minimum wage. On the other hand, wage increases, especially in the public sector, depend mainly on seniority. The combination of these two features is often viewed as an important cause of the dramatic increase in the wage differential between younger and older workers observed during the last two decades. Instead of inducing a natural substitution between older and younger workers, the existence of this wage differential is often taken as a justification for early retirement policies, especially in the case of industries affected by negative sectoral shocks, which have only caused a dramatic exit of older workers, with little incentives for new entry of younger workers (Contini 2005).

A very popular explanation for the rigidity of the Italian labor market is its institutional features, especially the strictness of the Italian Employment Protection Legislation (EPL). The available empirical evidence about the effects of the EPL on aggregate labor dynamics ${ }^{2}$ indicates that the EPL affects the composition of employment. In particular, countries like Italy where the EPL is stricter tend to display higher youth unemployment. ${ }^{3}$ Figure 6.4 shows the relationship between youth unemployment and an index of EPL strictness for some European countries in 2003. The index we use is Version 2 of the overall EPL strictness index computed by the Organization for Economic Cooperation and Development (OECD) in its 2004 Employment Outlook. Although Italy had been scoring at the highest level until the late 1990s, the changes to the temporary employment legislation introduced in the last two decades have somewhat lowered its EPL index. Table 6A.1 in the appendix shows the EPL index and its components as computed by the OECD in its 1999 and 2004 Employment Outlook. We report data for

2. See, for example, Bentolila and Bertola (1990) and Bertola (1999).

3. See OECD (1999) for a survey on the main empirical evidence about the effects of the Employment Protection Legislation on the aggregate labor market. 


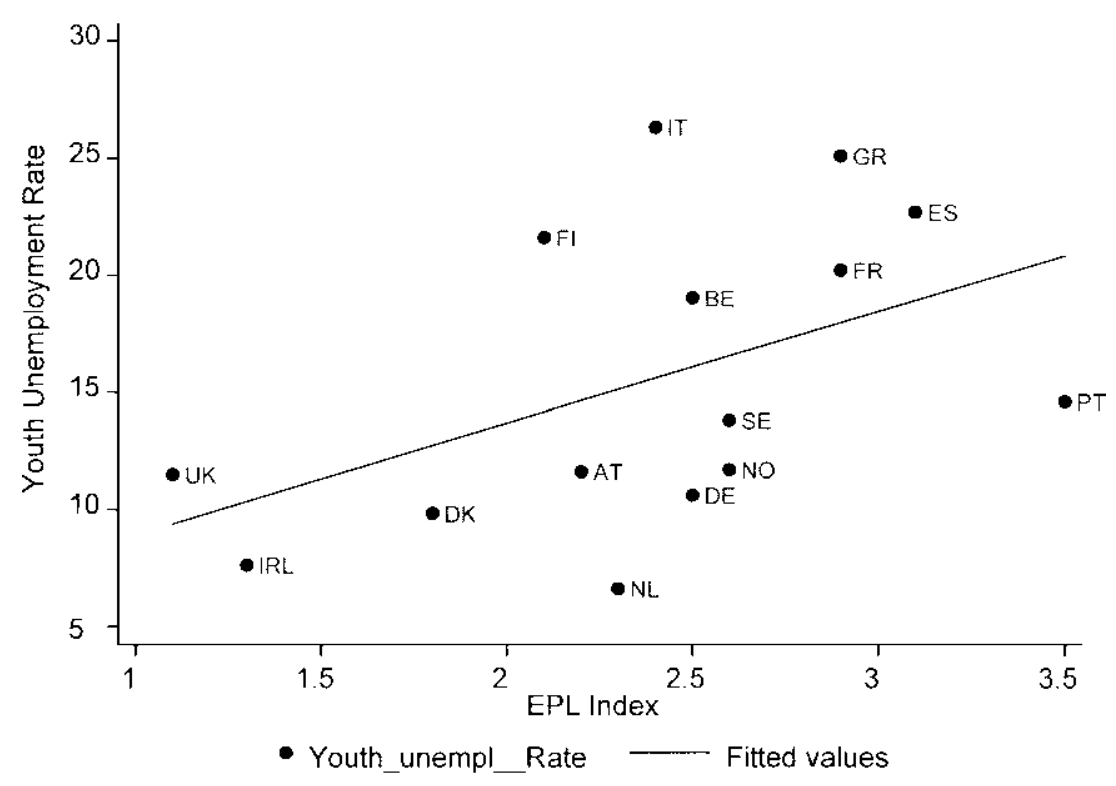

Fig. 6.4 EPL index and youth unemployment rate in Europe

Italy and a few other European countries (France, Germany, Spain, and the United Kingdom). It is clear that the Italian EPL is particularly restrictive on two dimensions: namely, "temporary employment" (although things improved substantially between the late 1980s and 2003) and "collective dismissal."

The "young in, old out" paradigm has been advocated in Italy mainly by trade unions and left-wing parties. With reference to the social security reforms of the 1990s and the more recent enactment of these reforms, one leading Italian trade union has argued that "one should not forget that raising the retirement age implies, not only that workers will be forced to work longer, but that two million jobs for the young will be lost." ${ }^{\text {4 Furthermore, }}$ the left-wing party "Rifondazione Comunista" claims that "the intergenerational exchange can be interpreted as the 50-years-old generation leaving their good jobs for the young. Would that be so dramatic for the social security administration? We do not think so." 5

Although Boldrin et al. (1999) clearly argue that the "lump of labor" story is not operating in Europe, one could get the impression that a "young in, old out" policy was pursued in Italy in the years between 1985 and 1990 as a result of the incentives for firms to hire younger workers (Contini and Rapiti 1999 ) and the incentives for workers to retire at very young ages (before age

4. Circolare Cobas, October 2003.

5. From the Web site of "Rifondazione Comunista," available at: http://www.rifondazione.it. 
fifty-five) due to the lack of any actuarial penalty on pension benefits. The overall effect on total labor force participation was basically close to zero, as the inflow of new workers balanced out with the outflow into retirement. However, this substitutability between workers of different age groups seems only temporary and in any case not "endogenous" but driven by separate determinants and partly by the business cycle. Indeed, the explanations for the changes in labor force participation, and particularly its composition, have been less straightforward after the year 1990 .

One interpretation starts from the observation that two contrasting trends have taken place: after a period of "jobless growth" during the 1980s and mid-1990s, a total reversal occurred, such that labor markets appeared fairly lively in contrast with a stagnant economy and an output growth close to zero.

Some authors (Boeri and Garibaldi 2007) have referred to a "honeymoon effect" of labor market policies in creating such discrepancies in observed patterns of employment and unemployment data on the one hand and output data on the other hand, taking effect well after the onset of the labor market reforms.

The claim of Boeri and Garibaldi is that there is a link between growthless job creation and the asymmetric labor market reforms in EPL carried out in several European countries in the 1990s. In fact, such reforms introduced in Italy a two-tier system, as the labor market became more flexible mainly through a series of marginal reforms that liberalized the use of temporary (fixed term) contracts while leaving unchanged the legislation applying to the stock of workers employed under permanent (open-end) contracts. These authors emphasize that the changes of EPL and their impact on labor demand do not produce any sizeable, permanent employment effects. ${ }^{6}$ The mechanism is that the reduction in EPL is bound to increase employment variability over the business cycle while not having any permanent effect on average labor demand. This is because EPL affects the incentives to both hire and to dismiss workers, and there is no reason to expect a priori that one effect could dominate the other.

Finally, some attention has to be devoted to reforms to the educational system, which have fostered the growth in school attendance-particularly at the university level. In 1969, a reform was passed that allowed access to the university from any secondary school; previously, only students coming from a "lyceum" could access. In the appendix, we present evidence ${ }^{7}$ for two groups of people: the "treatment group" is comprised of people who could benefit from the reform, as they were around age twelve at the time of the reform (young cohorts), while the "control group" is comprised of people

6. See also Bentolila and Bertola (1990) and Bertola (1990).

7. The data set used is the Survey of Income and Wealth, conducted on behalf of the Bank of Italy for several years. 
who could not benefit, as they were much older. In figures $6 \mathrm{~A} .1$ to $6 \mathrm{~A} .3$, we look at the status of these people well after the university age. In particular, we are interested in the difference in the prevalence of people by educational attainments. It is clear that the educational reform of 1969 has encouraged people to obtain a secondary school "diploma" and also a university degree (laurea). This is particularly evident for women.

\subsection{Main Features of the Social Security System}

The Italian social security system is based on a variety of institutions administering public pension programs for different types of workers (private-sector employees, public-sector employees, self-employed, and professional workers). ${ }^{8}$ All programs are of the unfunded pay-as-you-go (PAYG) type. Despite a process toward convergence during the 1990s, the various programs maintain quite different rules.

Currently, about two-thirds of the labor force is insured with the National Social Security Institute (INPS). The institute is responsible for a number of separate funds, of which the most important covers the privatesector nonagricultural employees (Fondo Pensioni Lavoratori Dipendenti or FPLD). Because the basic aspects of the system are well documented elsewhere (see Brugiavini [1999], Franco [2002], and Brugiavini and Peracchi [2004]), we describe very briefly its main rules (eligibility, pensionable earnings, benefit computation, indexation, and taxation of benefits).

Starting in 1992, a sequence of legislated changes thoroughly modified the social security system, originally designed in 1969. The main reforms took place in 1992, 1995, and 1997. They are known, respectively, as the Amato, Dini, and Prodi reforms, from the names of the prime ministers at the time. In addition, smaller changes to the system have been made nearly every year since 1992. Of the three main reforms of the 1990s, the Dini reform appears as the most radical, because it completely redesigns the system by modifying the eligibility rules and by changing the benefit formula back from defined benefits to defined contributions, which was the type of formula in place prior to 1969 . However, because it will only be introduced gradually through a very long transitional period, the direct effects of the Dini reform may be considered small compared to the less radical Amato reform.

Overall, because of the long transitional periods, the cohorts that reached the retirement age during the 1990s and those currently retiring remained largely unaffected by the reforms of the 1990s, as most of the burden of

8. "Social security system" and "pension system" in this chapter are used as synonyms. In fact, in Italy, social security is the main source of publicly provided income in old age. Contributions are compulsory for employers and employees, and benefits are earnings related. There is only a minor flat component granted to very old people (over sixty-five) under means testing if the beneficiary has no other income. 
the adjustment fell on the younger cohorts (Franco 2002; Brugiavini and Galasso 2003). More precisely, the 1992 (Amato) reform explicitly distinguished between workers with at least fifteen years of contribution at the end of 1992 and all other workers. The old system (introduced in 1969) applied, with some changes, to the former, whereas the new system only applied to the latter. The adoption of different rules for older and younger workers was maintained in the subsequent 1995 (Dini) reform and 1997 (Prodi) reform. In particular, with the exception of the new eligibility rules, very few changes applied to workers with eighteen or more years of contribution at the end of 1995 beyond those already introduced in 1992.

The following list of legislative changes highlights the exogenous variations in benefits envisaged by the reforms that are potentially relevant to our study and that in an ideal data set could be identified. We limit ourselves to the years 1976 to 2004, corresponding to the sample period, and focus particularly on changes that affect the decision to retire- - hence, particularly on changes to eligibility rules.

- In 1992 (Amato reform), the age requirement for an old-age pension gradually increased by one year of age every two years, starting from 1994, until reaching age sixty-five for men and age sixty for women in 2002.

- The new requirements for an old-age pension (age sixty-five for men and age sixty for women) applied starting in 1994 to managers and self-employed workers. Also in 1994, the requirement was set at age sixty-five for central government employees (irrespective of gender) and age sixty for local government employees (again, irrespective of gender). The old requirements remained unchanged for a few special categories (army and police personnel, flight personnel, traveling personnel of public transportation services, firemen, and employees of the entertainment industry).

- The number of years of contribution required for an old-age pension gradually increased by one every two years, starting from 1993, until reaching twenty years of contribution in 2000 .

- For workers with less than fifteen years of contribution at the end of 1992, the reference period for computing pensionable earnings gradually increased until it included the whole working life, with past wages adjusted to inflation on the basis of the annual rate of change of the cost-of-living index increased by 1 percent.

- New rules for combining pensions and earned income applied to pension granted after 1992: seniority pensions now could not be combined with earned income, whereas disability and old-age pensions could be combined, but only partially. The possibility of combining seniority pensions with income from self-employment was subsequently reintroduced in 1993. 
- Pensions were automatically adjusted only to the changes in the cost of living.

- In 1995 (Dini reform), the payroll tax rate increased from 27 percent to 32 percent.

- There was a gradual introduction of an age limit for seniority pensions, equal to age fifty-seven for both men and women in the year 2008.

- A new defined contribution (DC) system based on notional accumulated contributions applied to workers who started their career after 1995.

- A "proquota" system applied to workers with less than eighteen years of contribution at the end of 1995.

- After 1995, the main changes were an acceleration in the introduction of the age limit for seniority pensions and further harmonization of the pension rules for public-sector and private-sector employees.

\subsection{Labor Market Legislation and Reforms}

The rigidity of labor market rules in Italy goes back to 1966 when legislation on unfair dismissals established that employers had either to reemploy the worker or pay him or her a generous severance lump sum. The payment was higher for firms with more than sixty employees. An important change took place in 1970 (Statuto dei Lavoratori) establishing that firms with fifteen employees or more had to hire back workers undergoing unfair dismissal and also pay them the foregone wages, while firms below fifteen employees were totally exempted from this rule.

The changes to the labor market legislation between 1970 and 2004 can be divided into four main periods (Boeri and Garibaldi 2007): pre-1985, between 1985 and 1997, between 1997 and 2003, and post-2003.

As for the first period, an important change occurred in 1985 when special hiring conditions were granted to firms for contracts that envisaged on-thejob training ("contratti formazione lavoro"). These were clearly aimed at reducing youth unemployment, and indeed, hiring of younger workers (age twenty-five or less) became sizeable, particularly in the industrial sector.

The second period goes from 1985 to 1997 . This is characterized by a wider use of fixed term contracts (if allowed by industry-level collective agreements) and a reorganization of public employment agencies (Law $28 / 2 / 1987$, number 56), which in principle should guarantee a more efficient matching process.

The first important landmark was the 1997 reform known as the "Treu Package." This included a reduction of the penalties occurring in the case of violation of the fixed term contracts' discipline (conversion of fixed term contract into an open-ended one). It allowed for temporary work agencies to operate in the labor market. Nonpermanent labor contracts were 
encouraged by reducing social security contributions and pension provisions into open-ended ones. The package also made it easier to rely on apprenticeship and work-training contracts and set further incentives for on-the-job training.

A fourth period started with the "Biagi Law" of 2003. New types of labor contracts came into life: job on-call, job sharing, supplementary work, and "lavoro a progetto," which slightly tightened the regime for the already existing short-term contracts (known as "Co.co.co").

Overall, the Treu Package and the Biagi Law regulated in a less restrictive way the labor market and opened the way to temporary contracts.

\subsection{Descriptive Evidence on the Italian Labor Market}

This section briefly describes the data sources used in the chapter and the way we constructed the key variables for the analysis. It then presents some descriptive evidence on the Italian labor market.

Our main data sources are the Labor Force Survey (Indagine sulle Forze di Lavoro) or LFS, conducted by the Italian National Statistical Institute (ISTAT), and the Survey of Household Income and Wealth (I Bilanci delle Famiglie Italiane) or SHIW, conducted on behalf of the Bank of Italy.

\subsubsection{The LFS Data Set}

The Labor Force Survey is a quarterly longitudinal survey that was first conducted in 1959. It was carried out every second working week of each quarter (i.e., January, April, July, and October) until 2004. From 2005, it is carried out continuously during the year. The Labor Force Survey covers 300 thousand households and 800,000 individuals distributed in 1,351 Italian municipalities. In this chapter, we use the quarterly Labor Force Survey data from 1977 to 2004.

The statistical units are de facto households, and the questionnaire is administered to all household members who are more than fifteen years of age. The classification of the individuals by employment status is based on the status that individuals self-report and on a series of answers regarding the job activity of the respondent during the week before the interview. Moreover, the classification of the respondent is constructed following a hierarchical process: first, the employed are identified; second, among all the nonemployed, the job seekers/unemployed (both previously employed and first-time seekers) are identified; finally, all the remaining individuals are classified as out of the labor force.

The definitions and classifications used in the Labor Force Survey are based on the principles stated by the International Labour Office in 1982, and are the result of the harmonization process that makes them comparable with the ones adopted by the European Union. In particular, the definition 
of "unemployed" has changed during the years. First, in 1984, the definition of "job seeker" was changed to capture the criterion of self-reported "willingness to work." In 1986, the definition was restricted to those individuals who self-reported to have actively searched for work. Finally, in 1992, the job-search period of the unemployed was limited to thirty days before the interview date.

\subsubsection{Trends in the Labor Force}

By making use of the different waves of the LFS, we can trace out the trends of the activity rates and of the employment/unemployment rates for different age groups in the population. In particular, these groups are as follows:

- Young: people aged twenty to twenty-four

- Prime age: people aged twenty-five to fifty-four

- Old: people aged fifty-five to sixty-four

However, we can look at finer disaggregations by age group, which may be relevant for certain aspects of the labor market (e.g., distinguish the group aged fifteen to nineteen from the group aged twenty to twenty-four). One advantage of our data sets is that we can also exploit, both for the LFS and the SHIW sample, important regional variations in the Italian labor market. In particular, we distinguish five geographical areas: northwest, northeast, center, southwest, and southeast.

The most intuitive description of the labor force trends by age group is provided by the time series presented in levels. One point to be stressed is that the labor force series have a break in 1993 due to the recording methods: the Italian Statistical Office has revised the series before 1993 so that the break is no longer visible in the labor force partipation rate and in the unemployment rate. ${ }^{9}$

Figure 6.5 shows the labor force participation rate for young workers and older workers and the unemployment rate for the young for the period from 1977 to 2004 . The vertical bars refer to the years of the social security reforms. The unemployment rate is defined in the usual way as the ratio between the unemployed and the active people. Hence, this rate is more sensitive to business cycle fluctuations than the employment rate, particularly for young people.

The descriptive evidence suggests that there is no simple relationship between the labor force participation rate of the old and the unemployment rate of the young. In the 1970s and 1980s, the labor force participation of the old declined steadily, while the unemployment rate of the young increased. It is only in recent years that the effect of the social security reforms are

9. We are grateful to the Italian Statistical Office (ISTAT) for allowing us access to the Modello di Analisi Regionale della Spesa Sociale (MARSS) database. 


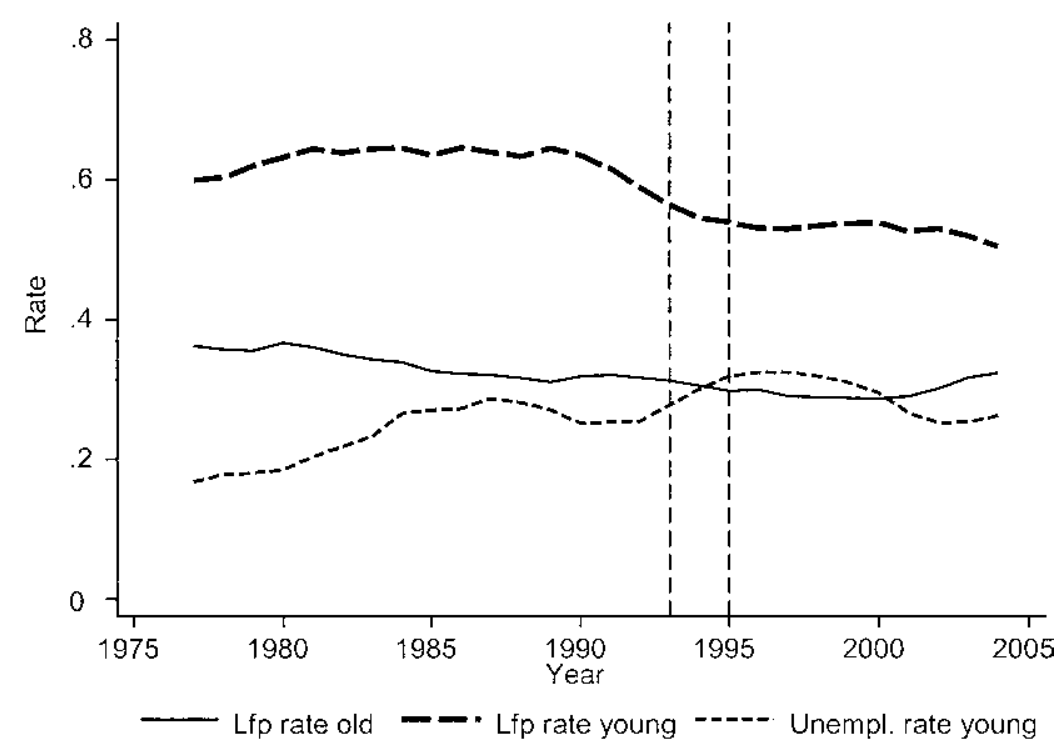

Fig. 6.5 Trends of labor force participation of young and old workers compared to the unemployment rate of the young

felt: a reversal of the declining trend in labor force participation is observed for the age group fifty-five to sixty-four (i.e., workers for which the age limits to access early retirement have gradually become binding) around the year $2000 .^{10}$

Overall, these trends suggest that the reforms had some impact: the youth unemployment rates decreased after 1997, while social security reforms increased labor force participation amongst the older workers.

There is no evidence of substitutability between older workers and younger workers. If anything, the two time series seem to be positively correlated: when the unemployment rate of the young increases, there are also more older workers leaving the labor market. The evidence of procyclical behavior is also confirmed by the time series of youth labor force participation.

The aggregate figures, however, conceal important gender differences. Figures 6.6 and 6.7 present times series evidence that distinguishes between male workers (figure 6.6) and female workers (figure 6.7). The unemployment rate of the young shows the same trends and cycles for males and females, with higher levels of unemployment for females in each year. The labor force participation of older workers also shows marked gender differences: male workers in the age group fifty-five to sixty-four exit the labor force at an increasing rate over time, apart from the reversal in the trend after

10. In the appendix, the same rates are presented in index form, where 1977 is the base year (set at one hundred). 


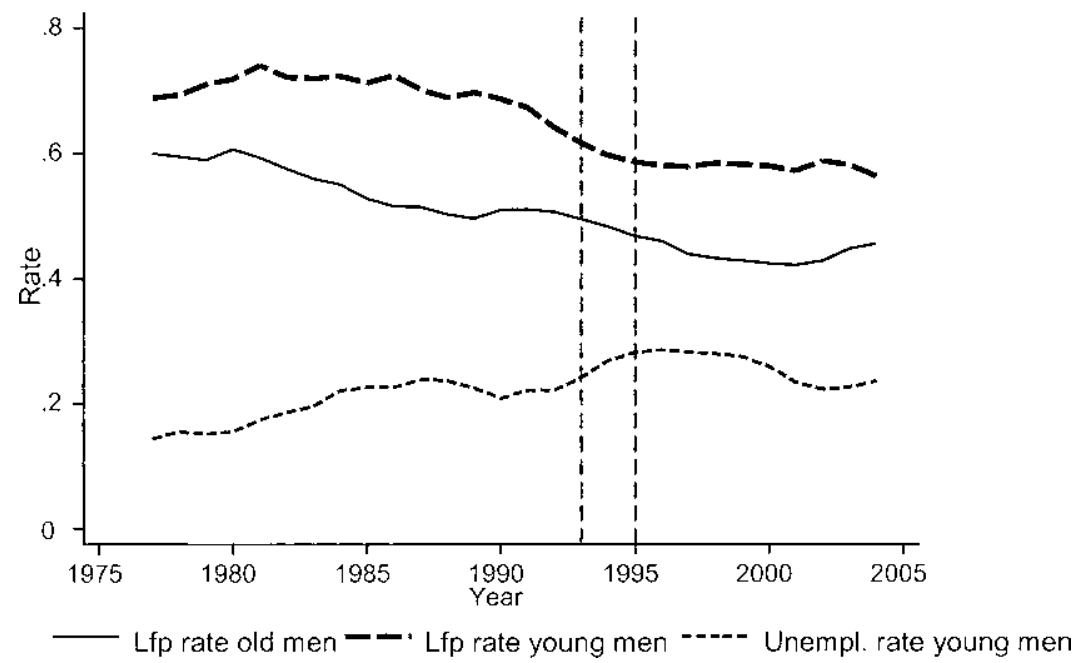

Fig. 6.6 Trends of labor force participation of young and old workers compared to the unemployment rate of the young: Males

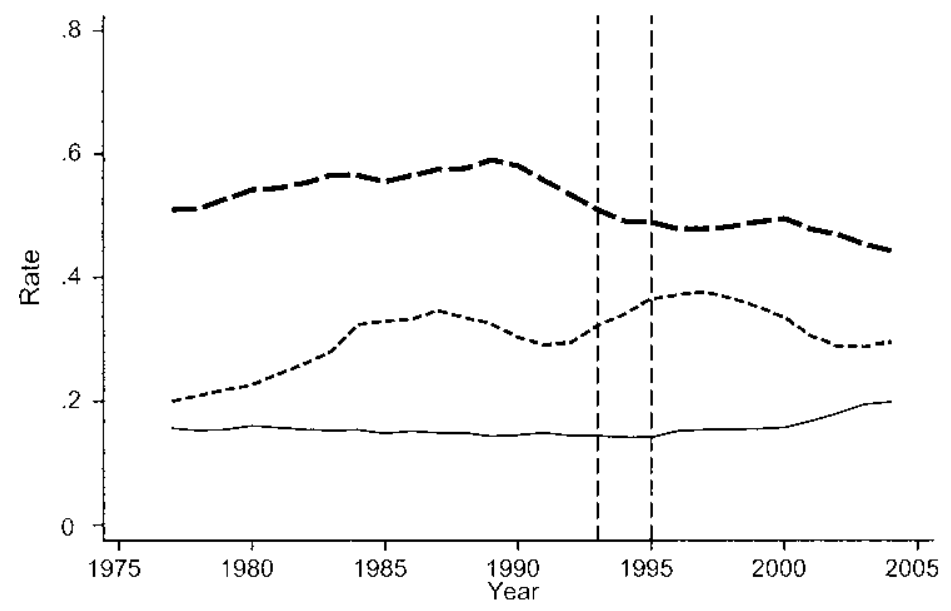

— Lfp rate old women $--L$ fp rate young women----- Unempl. rate young women

Fig. 6.7 Trends of labor force participation of young and old workers compared to the unemployment rate of the young: Females

the year 2000; for female workers of the same age group, the time series is flat or even increasing due to relevant cohort effects.

Figure 6.8 shows the same patterns, but the emphasis is on the trend in the unemployment rate of prime age workers (age twenty-five to fiftyfour). For this age group, the unemployment rate is at a much lower level, hence confirming that youth unemployment is the main determinant of total unemployment (see also figures 6.9 and 6.10). 


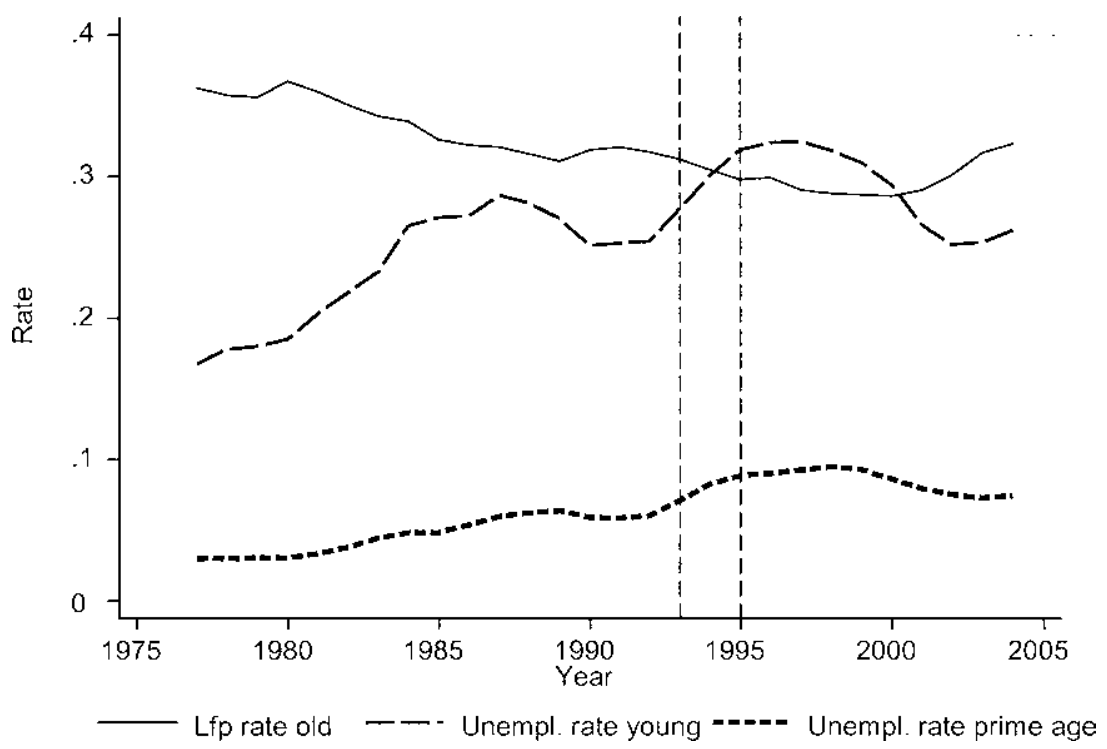

Fig. 6.8 Trends in the labor force participation rate of the old and unemployment rate of the young and prime age

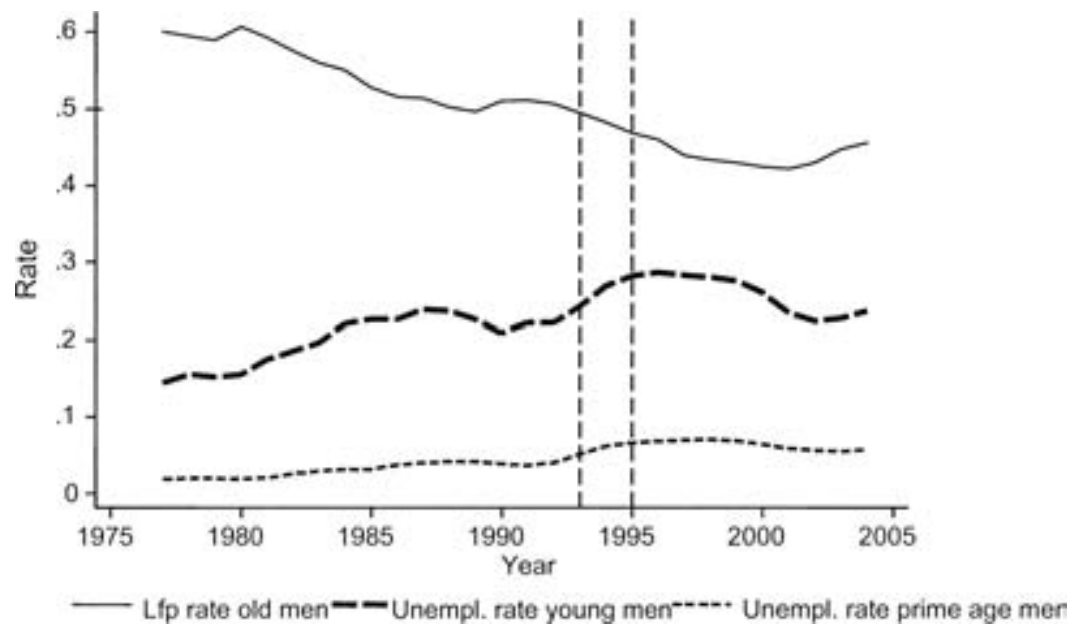

Fig. 6.9 Trends in the labor force participation rate of the old and unemployment rate of the young and prime age: Males

Figure 6.11 stresses once more that the labor force participation of the younger group and of the older group are procyclical. The decline in labor force participation of the young occurring in the late 1980s and early 1990s is largely due to increasing participation in schooling and to the rigidity of the labor market in those years. Only in recent years is the labor force participation rate of the elderly reversing the trend thanks to the pension reforms. 


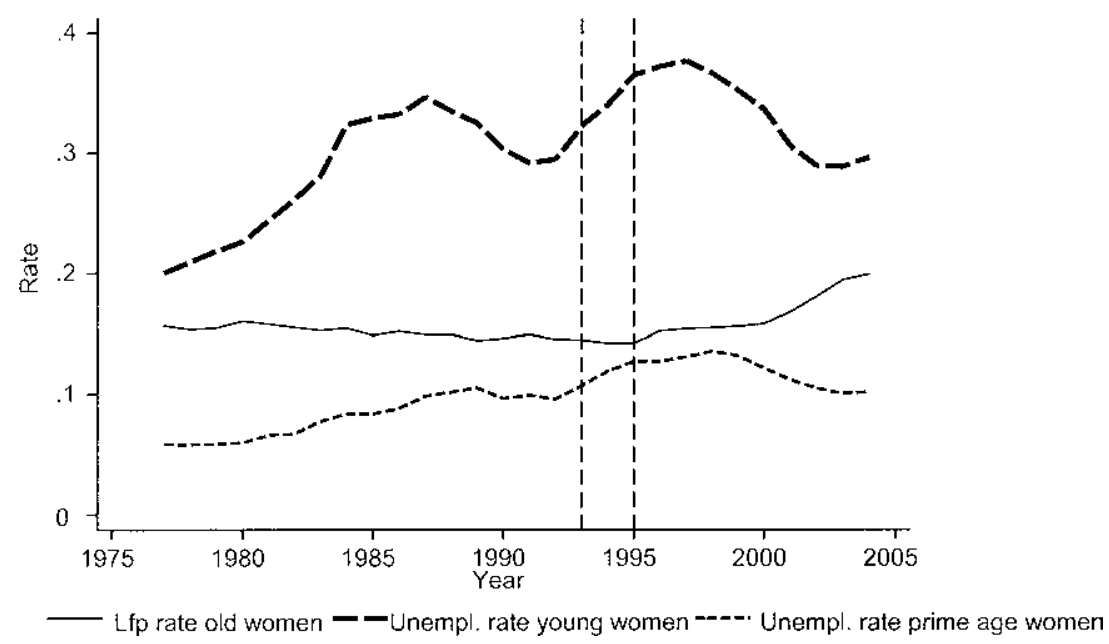

Fig. 6.10 Trends in the labor force participation rate of the old and unemployment rate of the young and prime age: Females

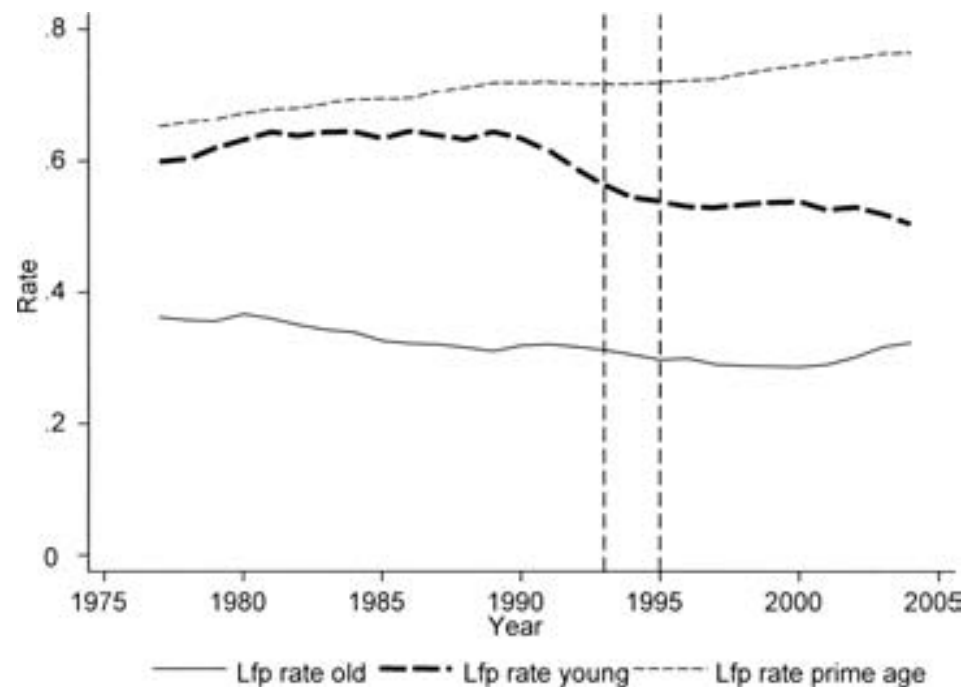

Fig. 6.11 Trends in the labor force participation rate of the old, the young, and the prime age group

For these trends, too, there is a clear gender difference: due to cohort effects, there is a growth in older female workers after the year 1997. For younger females, the pattern is similar to that observed for younger males, as schooling also plays an important role in this case (see figures 6.12 and 6.13).

As for the exits from the labor force, Italy has two main routes: old-age 


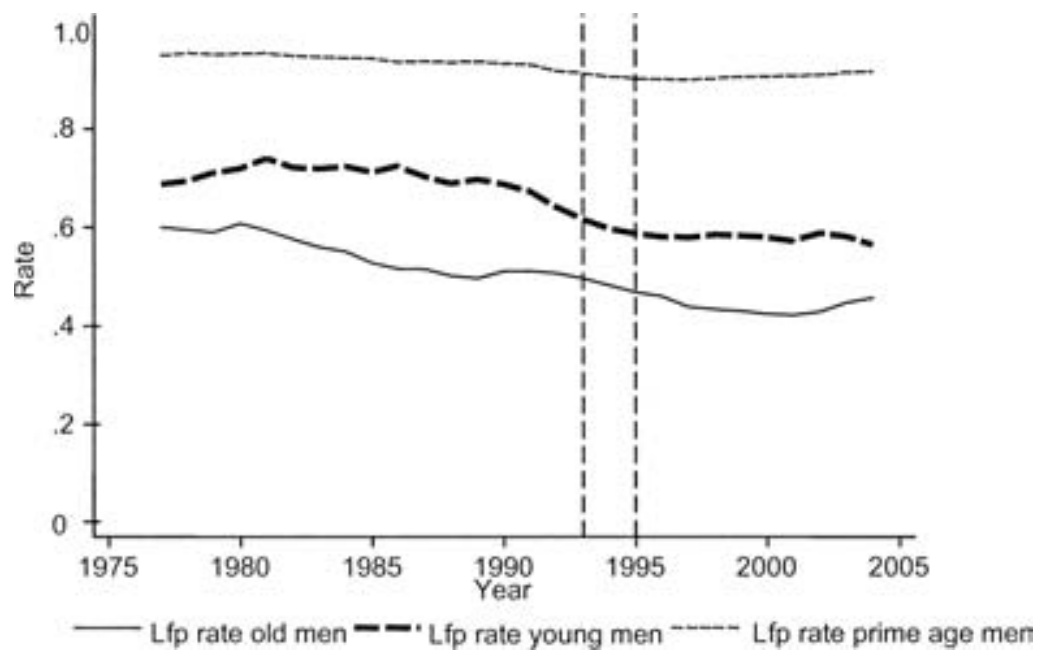

Fig. 6.12 Trends in the labor force participation rate of the old, the young, and the prime age group: Males

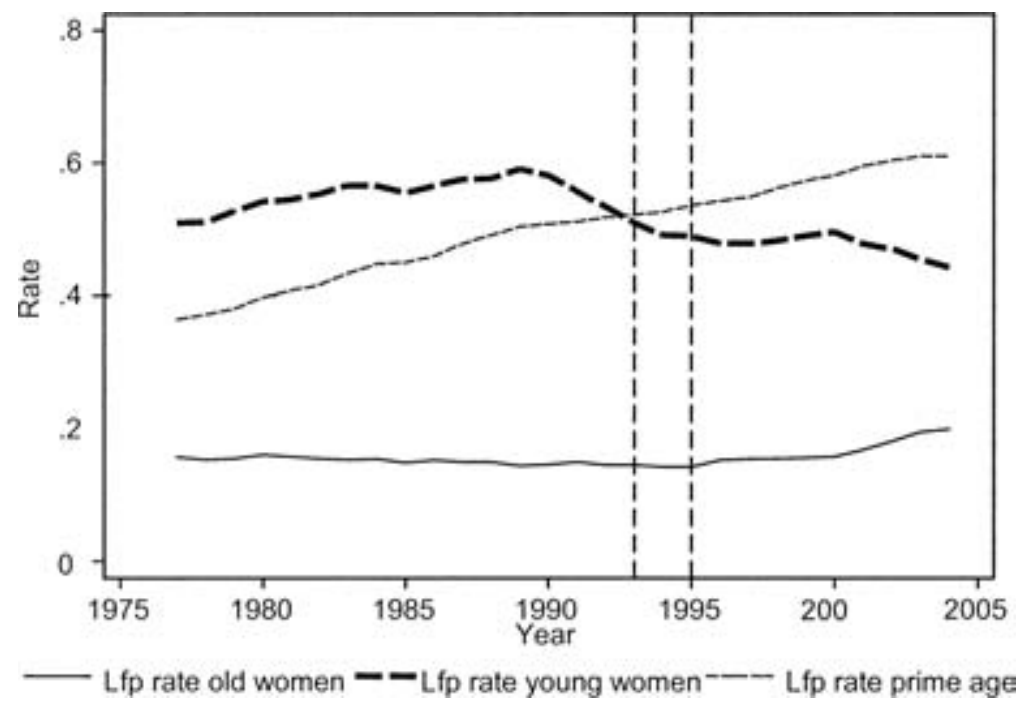

Fig. 6.13 Trends in the labor force participation rate of the old, the young, and the prime age group: Females

and early retirement. Invalidity pensions were relevant until the beginning of the 1980s, but regulation on access to invalidity benefits became much stricter in those years, and the inflow of such benefits was driven down to very small numbers within a ten-year period.

Figure 6.14 shows the composition of the stock of outstanding benefits 


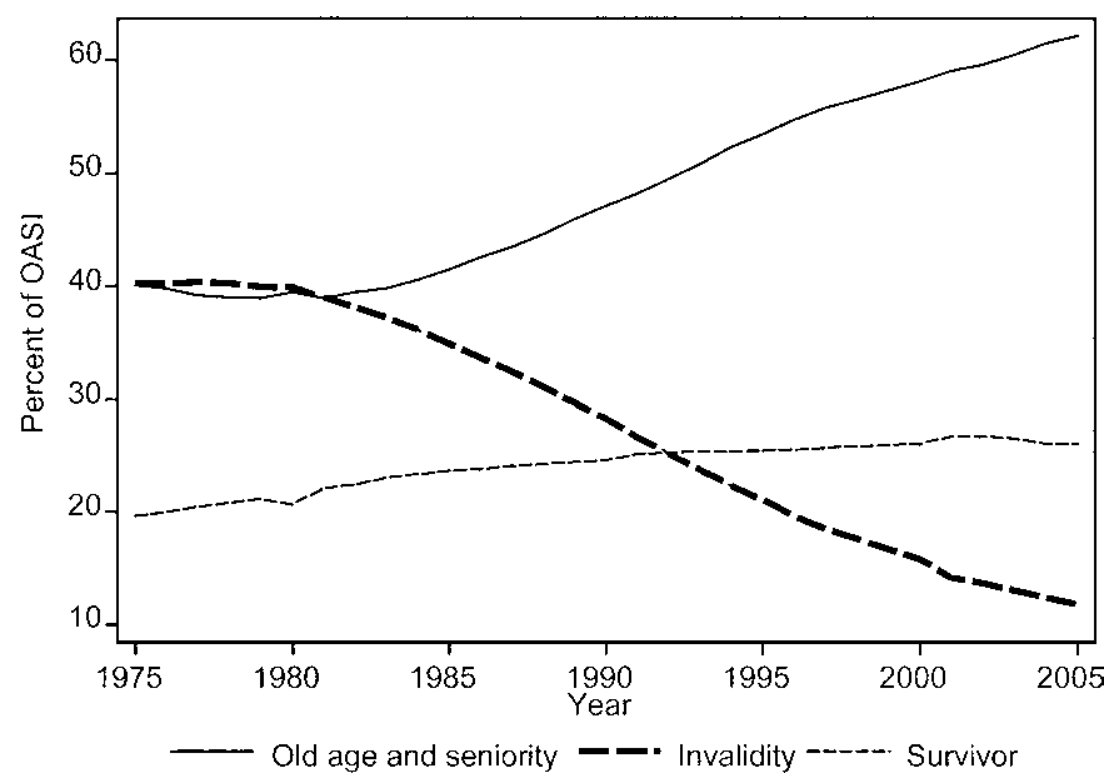

Fig. 6.14 Benefit recipients by type of benefit and year

by type of benefit and year. ${ }^{11}$ The stock of disability (invalidity) pensions is very high until 1984, but it goes down slowly over time as beneficiaries age and eventually die.

Figures 6.15 and 6.16 show the evolution of the stock of early retirement/ old-age benefits. From the year 2000, we can distinguish by age class. Under the assumption that in the age brackets fifty to fifty-four and fifty-five to fifty-nine we find early retirement benefits and that in some cases these are also claimed between the ages sixty and sixty-four, one can draw the conclusion that the restrictions on eligibility rules for early retirement have indeed been biting in recent years.

\subsection{Incentives to Retire}

In order to capture the effects of changes in legislation, particularly the effects of pension reforms, we compare the time series behavior of the incentives with that of the labor force.

We develop a simulation method to construct our incentive measures: this way, we can embed, in each year, legislated changes in the social security system (i.e., changes to benefit calculation and eligibility rules) while at

11. ISTAT, Casellario delle Pensioni. 


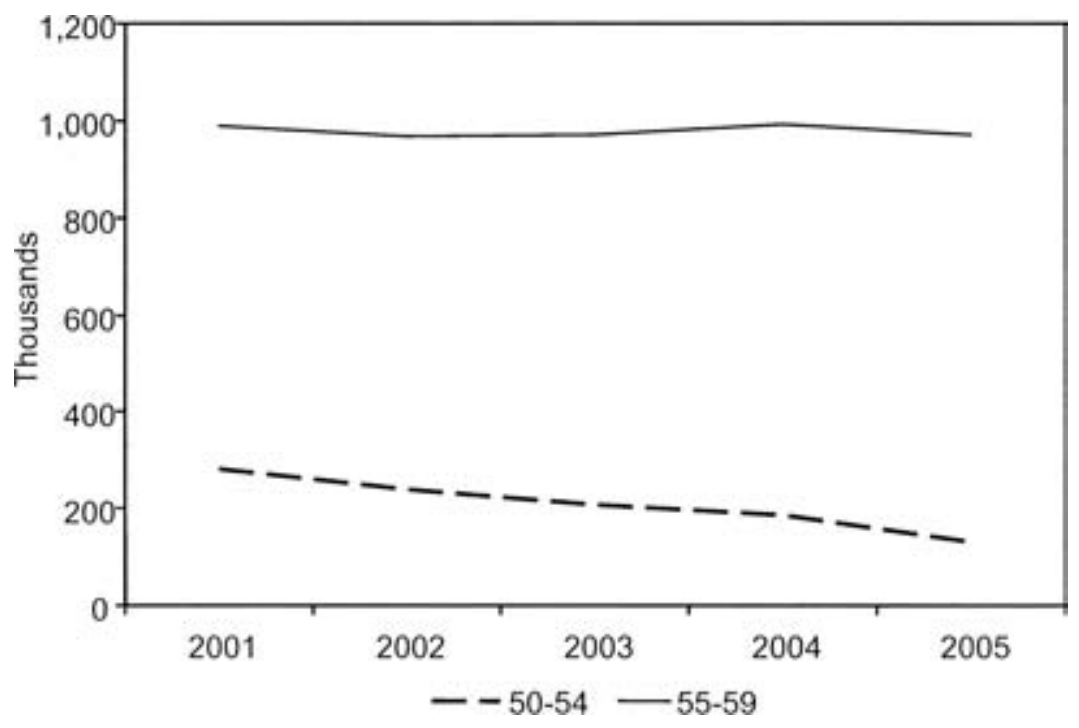

Fig. 6.15 Number of recipients of early retirement/old-age social security

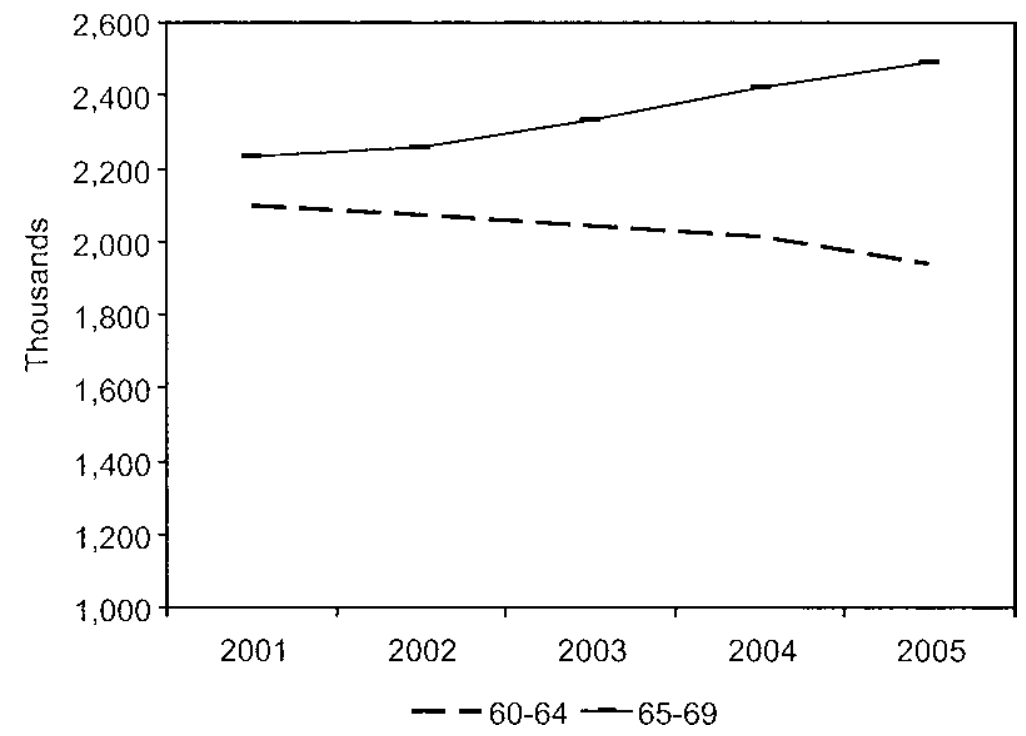

Fig. 6.16 Number of recipients of early retirement/old-age social security 
the same time avoiding the endogeneity problems contaminating the actual social security data series.

In order to carry out this simulation (based on Brugiavini and Peracchi [2005]), we make use of the SHIW data, which contains detailed information on the personal characteristics that are needed to compute or approximate pension benefits under the various regimes.

\subsubsection{The SHIW Data}

The SHIW is a repeated cross-sectional survey that was first conducted in 1965. It was carried out annually until 1987 (except for 1985), then every two years until 1995, and then again in 1998, 2000, and 2002, the last used in this chapter. The 2002 survey covers about 8,000 households and 21,000 people. From 1989, the survey also contains a panel component. Currently, about half of the sample (4,000 households in all) is included in the panel. In this chapter, we use the historical database (Bank of Italy 2004), which contains the harmonized microlevel data for the whole period from 1977 to 2002 .

The survey units are de facto households. All household members (including those aged less than fifteen) are asked to indicate their income in the year before the survey. Questions about the household are submitted to the head of the household (see also the appendix for details). Because of oversampling of certain population strata in some years (especially in 1987) and differential nonresponse and attrition rates, it is crucial to use the survey weights when estimating population features such as means, variances, and percentiles.

The quantity and quality of the information collected by the survey increased over time. For example, until 1983, age was only recorded in broadly defined brackets. From 1984, age has been recorded in years, so one can study the behavior of birth cohorts defined by single years of age. Until 1989, little information was available for those who did not receive any income. Basically, only gender, age, relationship to the head, and main activity (housewife, student, etc.) were recorded, but there was no information on, for example, educational attainments and marital status. The frequent changes in the definitions complicate the task of constructing time-consistent measures. This is particularly true for variables such as the schooling level, the sector of employment, and the type of job. However, the "historical archive" of the Bank of Italy provides harmonized measures that mostly overcome these problems for the purpose of this study.

\subsubsection{Incentive Measures}

Before turning to the simulation methodology, we look at a simple measure capturing changes in eligibility rules: this is the sum of minimum age requirements and the number of years of seniority necessary to apply for an early retirement benefit. In fact, workers could retire in Italy either when they 
reached a certain age (the legal retirement age for old-age benefits, which is now sixty-five for men) or a certain number of years of contribution (for example, any age if forty years of contribution had been completed) or a combination of the two (for example, fifty-seven years of age and thirty-five years of contribution). We call this sum the "quota": before 1995, the quota was not defined, as individuals could retire at any age. It was introduced in 1995 at level eighty-three and increased gradually thereafter.

Figure 6.17 shows the relationship between the unemployment rate of the young, the employment rate of the old, and the "quota" variable. The quota "index" keeps growing until the most recent years, while the unemployment rate of the young shows a relevant swing. The jump in the "quota" indicator anticipates by a few years the rise in employment of the old group.

Because the "quota" variable is a rather rough measure of the complex financial incentives of the social security system, we construct a set of incentive measures that capture different dynamic features of the social security system.

\subsubsection{Social Security Wealth and Incentives}

The SHIW sample offers considerable variation, which reflects both the differences in individual characteristics and the different rules of the pension system for different categories of workers: private-sector employees, public-

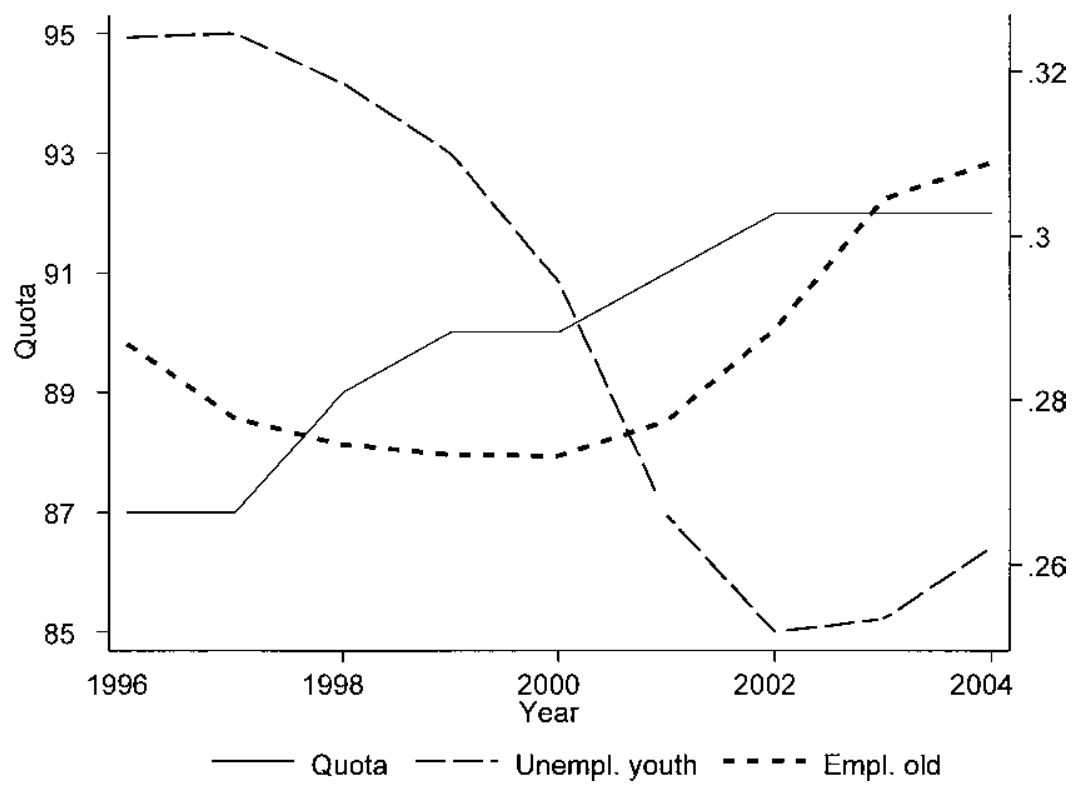

Fig. 6.17 Trends in the unemployment rate of the young, the employment rate of the old, and the "quota" variable 
sector employees, and the self-employed (in this chapter, we refer to these as "employment types" or simply "jobs").

To compute the simulated benefits, we start from the profile of median earnings for a given cohort. As in Brugiavini and Peracchi (2004), we focus on cohorts born before the Second World War; in particular, individuals born in 1938 and 1939. We estimate their earnings profiles by gender and by employment type (private employee, public employee, and self-employed). We then smooth the earnings profiles by means of age polynomials and also by nonparametric smoothers. The same estimated earnings profile is then imputed (taking account of the relevant job-gender group) for all members of that group. Productivity growth of the different cohorts is attributed by shifting the age profile. ${ }^{12}$

Simulated benefits are obtained by applying the prevailing legislation for each employment type, taking account also of eligibility rules. For example, we model the reform of 1992 (implemented in 1993) known as the "Amato" reform as follows. Changes affected both currently retired people (through a reduced indexation based on inflation only) and future retirees through changes in the benefit calculation, eligibility rules, and indexation of future benefits (see Brugiavini and Peracchi [2004] for details). Hence, effects on current variables, such as social security benefits, are immediately captured after 1992, both because of the effects on pensioners and because of the changes (gradually less and less generous) to newly awarded benefits during the transitional period. It should be noted that there are differences both in the way rules changed for different types of employees and in the way these changes impacted individual behavior (e.g., consumption), because these groups of the population started from different conditions (publicsector employees had more generous pensions to start with). All monetary amounts are measured in euros at constant 2005 prices.

Although several changes have been made to the benefit computation rules, eligibility rules remained almost unchanged in the relevant years until the 1992 reform. Also, the existence of a generous early retirement option allowed retirees to have plenty of flexibility on the timing of retirement, so the introductions of more restrictive eligibility rules in the early 1990s had little impact on the current cohorts of retirees. The effects of the minimum requirements have been felt more recently, especially for the younger old.

Figure 6.18 provides a graphical representation of social security wealth by year and cohort for a hypothetical "median wage earner" of that cohort. The cohort-specific time series are obtained as weighted averages of the social security wealth of men and women of different employment type.

12. Growth rates in earnings for the different cohorts are computed on the basis of two sources: Rossi, Sorgato, and Toniolo (1993) for the data before 1990 and the SHIW data set for the more recent years. 


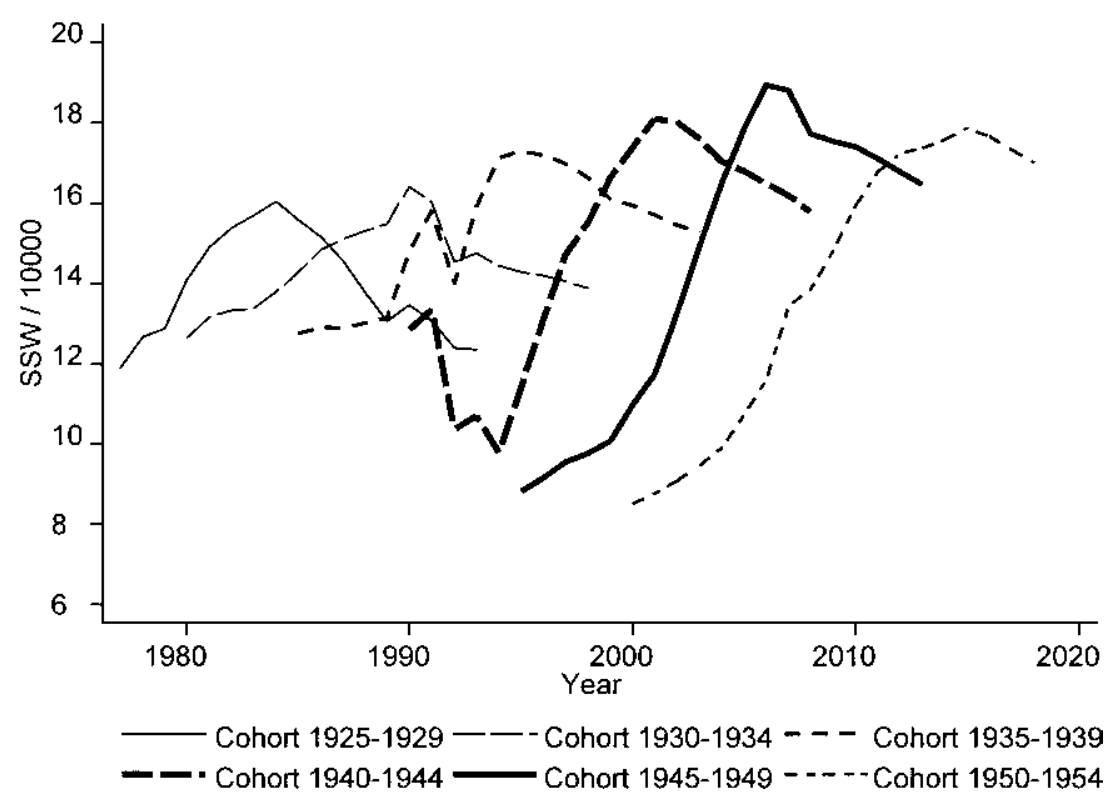

Fig. 6.18 Social security wealth $(W)$ by cohort and year (pooled data)

For each cohort, the pattern is generally hump-shaped; that is, social security wealth $(W)$ reaches a peak at some eligible age, and it then declines thereafter. Besides a secular increasing trend in the level of $W$, one can observe also a corresponding trend toward larger dispersion: after the reforms of the 1990 s, $W$ starts at a lower level and reaches a peak at a much older age. Part of this variability across cohorts is also due to changes in productivity and in mortality. ${ }^{13}$ It is clear that changes in eligibility conditions, particularly the minimum age requirement for access to early retirement, play an important role in shaping the SSW profile. Changes in the benefit computation rules occurring after 1992 explain why retirees who claim early retirement would have low benefits due to lower average "pensionable earnings," despite the lack of an actuarial penalty for early retirement in Italy.

When aggregating the age-year values of social security wealth, one obtains a yearly index of the incentives faced by different cohorts in that particular year. We make use of two incentive measures, both weighted averages: the first one is called $\bar{W}$ and is the weighted sum of $W$; the second is called $\bar{I}$ and combines both the level of social security wealth and its

13. We experimented by fixing both the productivity and the mortality probabilities so that the only variability is in the age-earnings profile and in legislation. Important variability across cohorts is still observed due to the reforms. 
peak value. The first measure $\bar{W}$ is a synthetic incentive measure that reflects the mean expected social security benefit faced by each cohort $a$ in year $y$ :

$$
\bar{W}(a, y)=\sum_{t=0}^{a-50} \frac{\operatorname{LFP}(a-t, y-t-1)}{\sum_{t=0}^{a-50} \operatorname{LFP}(a-t, y-t-1)} W(a-t, y-t) .
$$

This is the average value of $W(a, y)$, the social security benefit, between the year when cohort $a$ becomes eligible for benefits and year $y$. Weights are based on labor force participation rates by year and cohort (data source: ISTAT). This formula is implicitly assuming that before age fifty (i.e., before eligibility), the social security benefit of cohort $a$ is zero. The rationale is that $W(a, y)$ takes into account the forgone benefit by a member of cohort $a$ if he or she decides not to retire in year $y$. Hence, if cohort $a$ is not eligible in year $y$, individuals of that cohort have no choice of whether to retire and therefore have no forgone benefits.

The next step is to build an aggregate measure of expected social security benefits across cohorts for a given year. This is done by averaging $\bar{W}(a, y)$ over the cohorts' population in a given year:

$$
\begin{aligned}
\bar{W}(y) & =\sum_{a=50}^{64}\left[\frac{P(a, y)}{\sum_{a=50}^{a=64} P(a, y)}\right] \bar{W}(a, y) \\
& =\sum_{a=50}^{64}\left[\frac{P(a, y)}{\sum_{a=50}^{a=64} P(a, y)}\right]\left[\sum_{t=0}^{a-50} W(a-t, y-t) \frac{\operatorname{LFP}(a-t, y-t-1)}{\sum_{t=0}^{a-50} \operatorname{LFP}(a-t, y-t-1)}\right],
\end{aligned}
$$

where $P(a, y)$ is the proportion of retired persons in the given year, estimated from the SHIW, and LFP is the labor force participation rate by year and age, taken from the Labor Force Survey. We regard age fifty as the first eligibility age. Because we exploit both gender and regional variation, this measure has been computed conditional on gender and macroregion and then aggregated at the national level.

Our second index is based on the peak value $\mathrm{PV}^{*}(a, y)$. The peak value is defined as the maximum present value of $W(a, y)$ for ages greater than $a$. This may vary with $y$, and it may also vary with age in a given year because of different earnings histories for the different cohorts. The index $I(a, y)$ takes into account both expected social security benefits and the peak value using a discount factor $\alpha$ and weights $q$, which represent the proportion of individuals in the labor force of a given age and in a given year (LFP):

$$
I(a, y)=\left\{W(a, y)+\alpha\left[W(a, y)-\mathrm{PV}^{*}(a, y)\right]\right\} q(a, y) .
$$

The peak value $\operatorname{PV}^{*}(a, y)$, consistently with the underlying measure $W(a, y)$, is set to zero if the current age is below the eligibility age. The value of the 
discount factor $\alpha$ will be chosen optimally, as discussed next. By averaging over the different cohorts, we obtain an annual time series $\bar{I}(y)$, defined as:

$$
\bar{I}(y)=\sum_{a=50}^{64}\left[\frac{P(a, y)}{\sum_{a=50}^{a=64} P(a, y)}\right]\left[\sum_{t=0}^{a-50} I(a-t, y-t) \frac{\operatorname{LFP}(a-t, y-t-1)}{\sum_{t=0}^{a-50} \operatorname{LFP}(a-t, y-t-1)}\right] .
$$

The intuition behind the index $I$ is to combine both the wealth effect generated by the social security wealth variable and the dynamic gains from waiting to retire. It captures the trade-off between a higher social security wealth $W$, which may induce the worker to retire early, and the gains from postponing retirement ( $W-\mathrm{PV}$ ), which represent the advantage of staying at work. The latter is discounted by the appropriate discount factor that depends on the impatience of the individual. If $\alpha=0$, we have the extreme case where individuals are so impatient that they do not take future gains or losses into account.

In order to obtain endogenously an optimal discount factor, we make use of two methodologies called, respectively, the iteration procedure and the regression approach. Both build on the simple relationship:

$$
\mathrm{LFP}_{\text {old }, t}=\gamma \bar{W}_{t}+\theta\left(\bar{W}_{t}-\mathrm{PV}_{t}\right)+\beta X_{t}+\varepsilon_{t},
$$

where $W$ and $(W-\mathrm{PV})$ are the two terms in the index $I, X$ is a matrix of controls, and $\varepsilon$ is a random error. The iteration procedure is implemented by setting $\gamma=1$ and letting $\theta$ vary on a given grid in order to maximize the $R^{2}$ associated with equation (5). The value of $\theta$ that gives the highest $R^{2}$ is chosen as the optimal $\alpha$. In the regression approach, we instead let both parameters $\gamma$ and $\theta$ vary freely and compute $\alpha$ as the ratio between the two.

Both indexes, $W$ and $I$, are computed by taking as benchmark the earnings of the median worker, estimated from the SHIW.

Table 6.1 shows the estimates of these parameters obtained from the two methodologies. We also distinguish the case where workers are "liquidity constrained" - that is, they cannot access their benefits before the eligibility age, and therefore both $W$ and ( $W-\mathrm{PV}$ ) are set to zero.

As it emerges from table 6.1, our preferred specification (the one delivering the highest $R^{2}$ ) according to the iteration method sets $\alpha=1.50$ both in the unconstrained and the constrained case. ${ }^{14}$ As for the regression method, we obtain opposite signs, which is counterintuitive, but these estimates are hardly significant. Hence, in the remainder of this chapter, we focus on estimates of the incentive effect on labor force participation obtained by setting $\alpha$ equal to 1.50 .

Figure 6.19 and 6.20 show the time series of our incentive indexes. The

14. It should be noted that in this chapter, $\alpha$ is exactly the discount factor presented in equation (3). 
$I$-index is more hump-shaped, as it reflects the dynamic in the peak value that emerges from figure 6.18. It is interesting to note that when liquidity constraints are introduced, the $I$-index is rather sensitive to this change, because for Italian workers, such constraints are binding by effectively reducing the access to early retirement benefits.

Figure 6A.4 in the appendix shows the effect of the different parameter configurations on the index $I$ : the higher is $\alpha$, the more pronounced is the

Table 6.1

Italy: Estimates of the parameters of the $I$-index

\begin{tabular}{lccccc}
\hline & \multicolumn{4}{c}{ LFP old } \\
\cline { 2 - 5 } & Gamma & Alpha & Ratio & $R^{2}$ & Ibar weighting \\
\hline \multicolumn{1}{c}{ Iterating over alpha with gamma $=1$, with 0.25} & intervals & and regressing LFP of old on ibar \\
Unconstrained & 1 & 1.50 & 1.50 & 0.8134 & $1 * W+1.50 *(W-\mathrm{PV})$ \\
Liquidity constrained & 1 & 1.50 & 1.50 & 0.8038 & $1 * W+1.50 *(W-\mathrm{PV})$ \\
& Time series regression of LFP old on $W$ and $(W-P V)$ \\
Unconstrained & 0.2991315 & -0.2480815 & -0.83 & 0.8201 & $0.299^{*} W-0.248^{*}(W-\mathrm{PV})$ \\
Liquidity constrained & 0.7126528 & -0.5474849 & -0.77 & 0.7809 & $0.713 * W-0.547 *(W-\mathrm{PV})$ \\
\hline
\end{tabular}

Note: $I$ is divided by 100,000 . The estimates of alpha and gamma for the regression method, though being of different sign, are not significant. Covariates have been used to estimate the best alpha, both in the regression method and in the iteration method. Covariates include: year, GDP per head, GDP per capita growth, median wage of the age group under study, percentage of people in school in the age group under study, and share of added value by industry on the GDP.

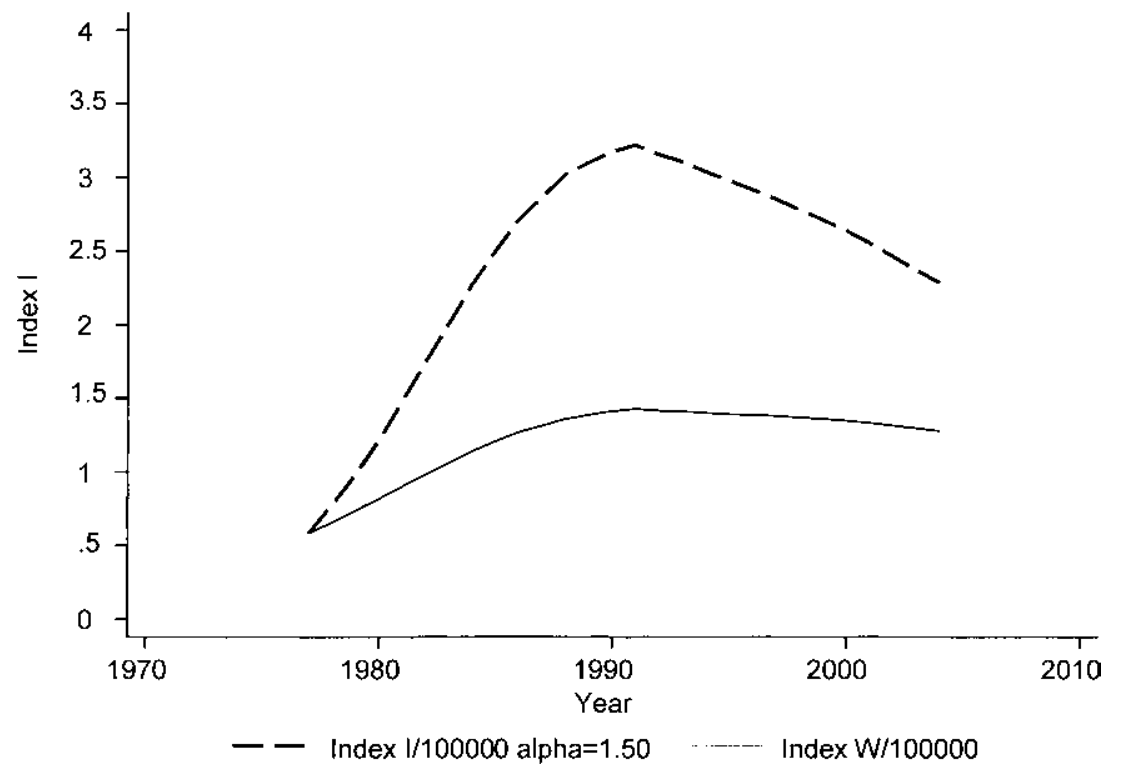

Fig. 6.19 Incentives to retire by year ( $W$ and $I)$, no constraints 


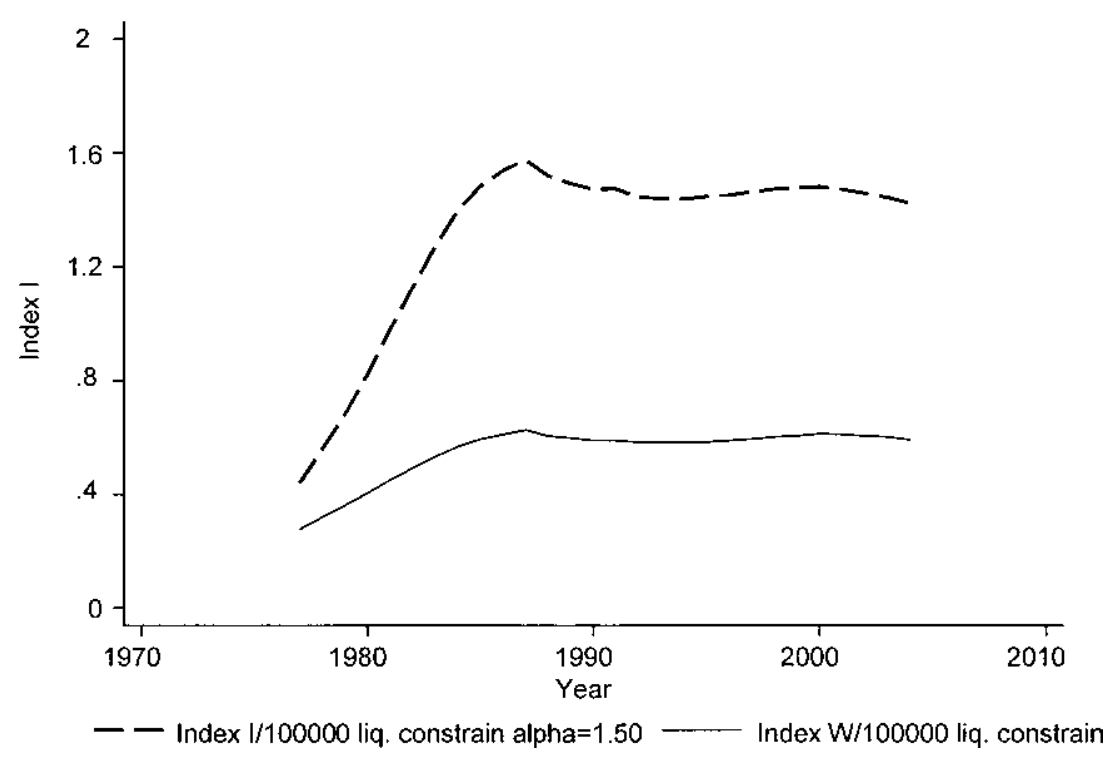

Fig. 6.20 Incentives to retire by year ( $W$ and $I)$, with constraints

hump. The index $W$ is dominated by the growth of the generosity of the system in the early years and by the fact that older cohorts started collecting benefits having completed full careers in the 1970s. The index $W$ peters out at the end of the 1990s, both as an effect of the reduced generosity and as a result of the demographic changes.

Figures 6.21 and 6.22 show the relationship between the index $W$ of equation (2), the index $I$, and the unemployment rate of the young and of the prime age group. Although there seems to be some correlation between the secular trends in the time series, this correlation vanishes after the reforms, when the unemployment rates fluctuate while the indexes decline steadily.

A similar picture emerges from figures 6.23 and 6.24, which relate the incentive measures to the employment rates of the young and of the prime age group.

\subsection{Regression Analysis}

Our descriptive evidence shows evidence of a negative correlation between the unemployment rate of the young and the labor force participation of the old. We argued, however, that this correlation may just be due to the underlying business cycle. Incentive variables, which represent our "instrumental variables" in capturing the possible nexus between pension policies and labor market trends, also seem to play a role in explaining the behavior of older workers (but presumably not of younger people). 


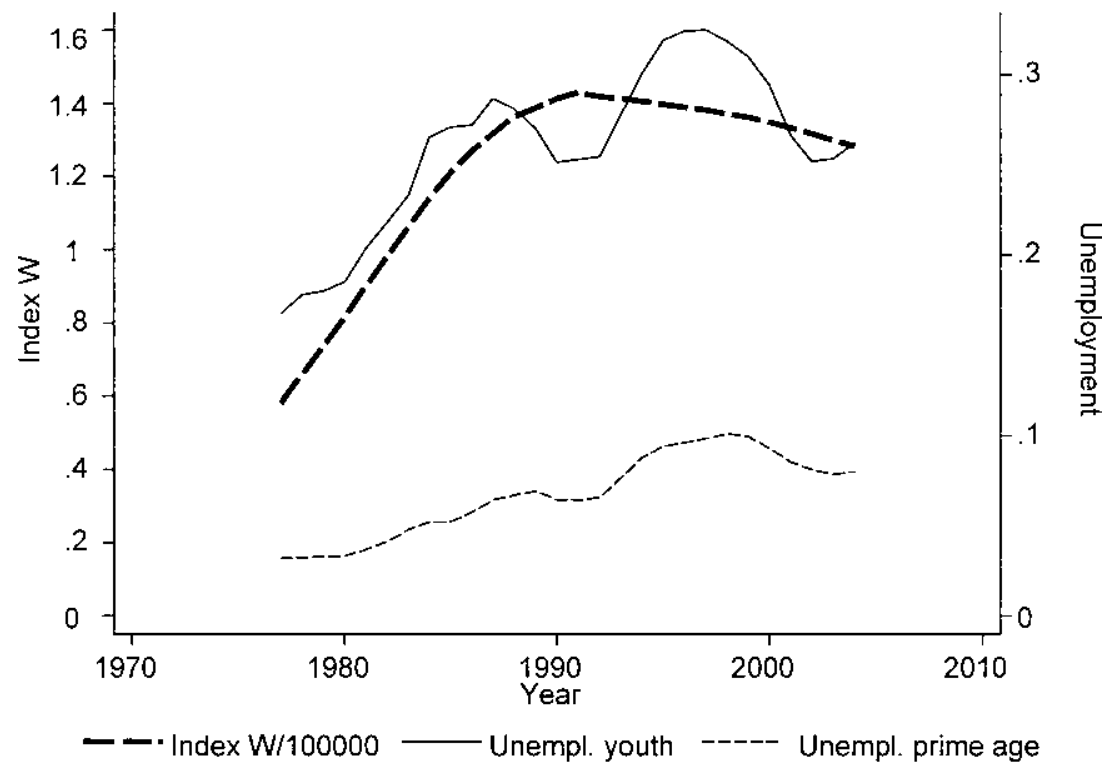

Fig. 6.21 Unemployment rate of the young and of the prime age group and the incentive variable $W$, no constraints

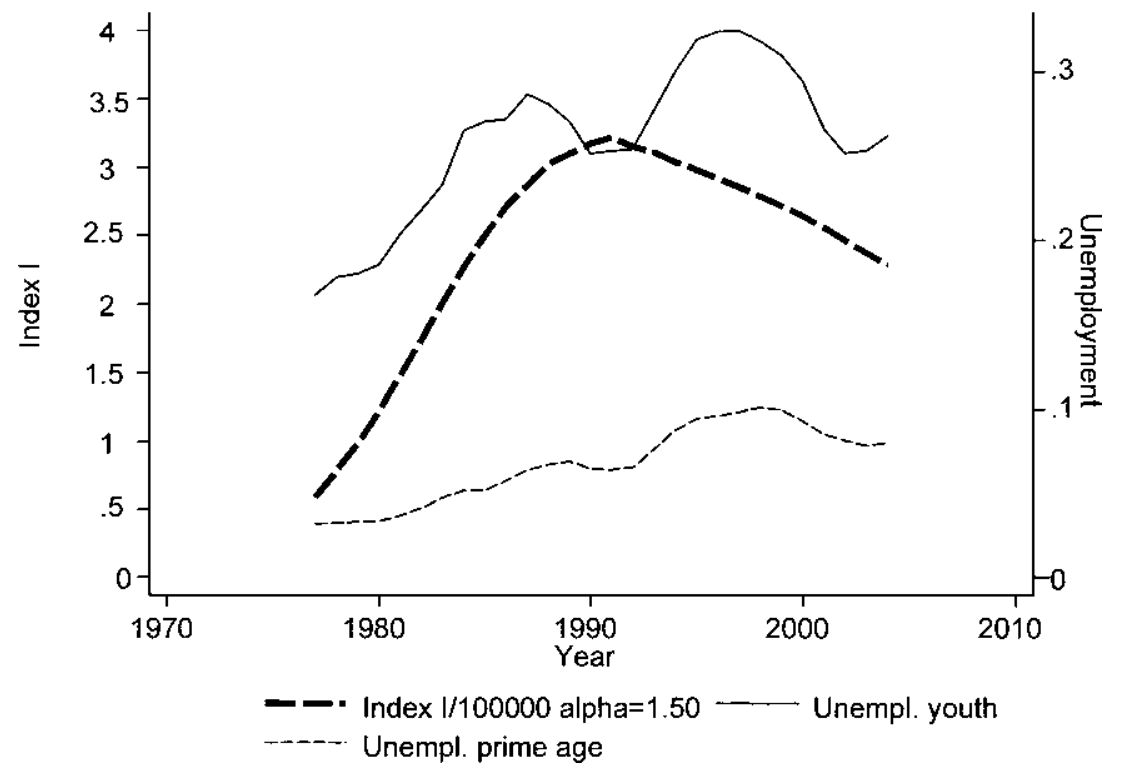

Fig. 6.22 Unemployment rate of the young and of the prime age group and the index $I$, no constraints 


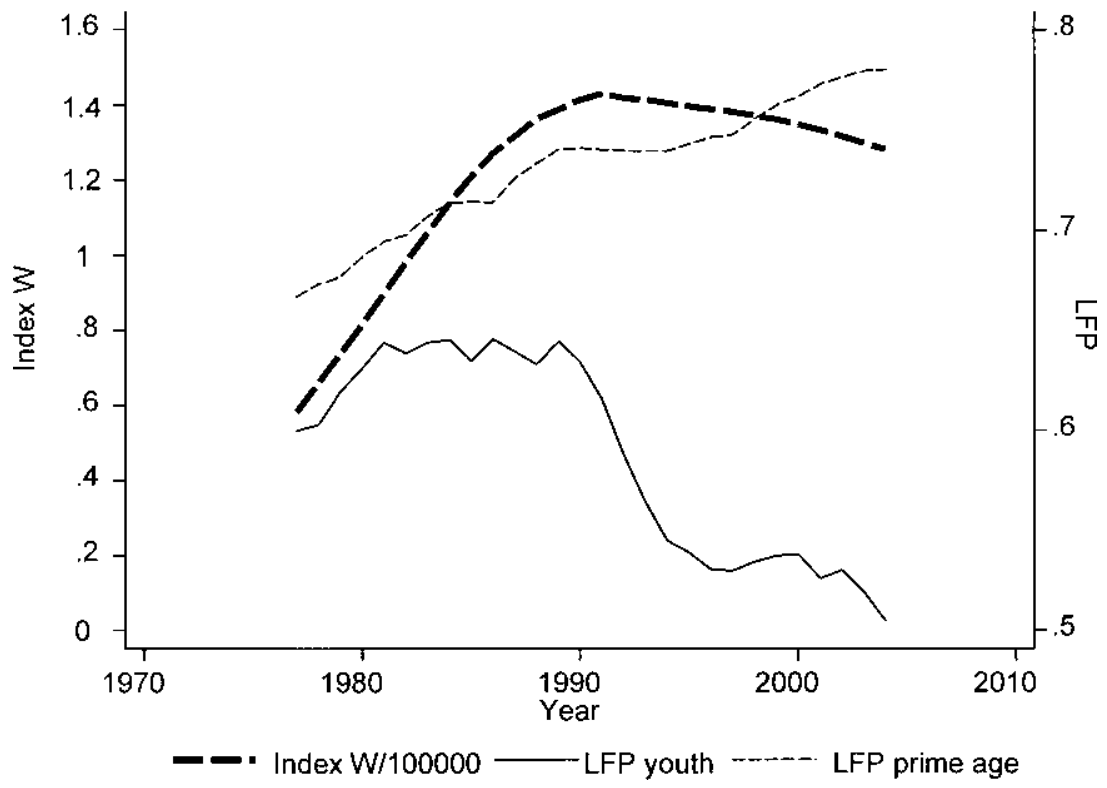

Fig. 6.23 Employment rate of the young and of the prime age group and the incentive variable $W$, no constraints

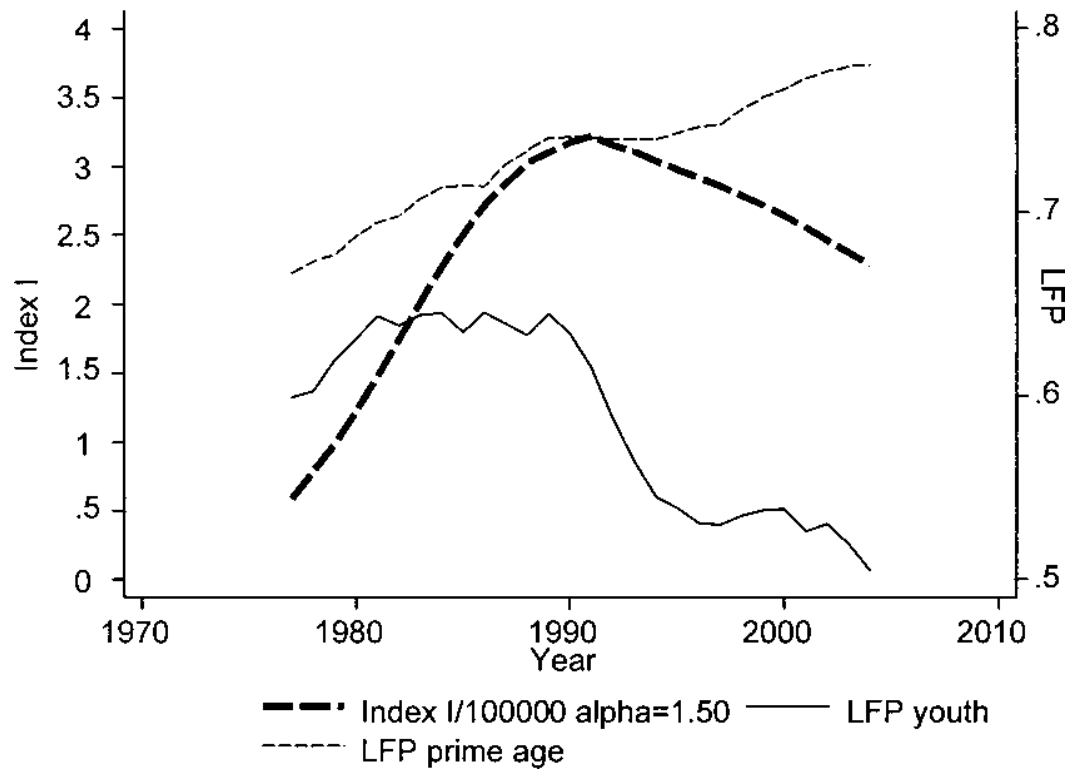

Fig. 6.24 Employment rate of the young and of the prime age group and the incentive variable $I$, no constraints 
These questions are better addressed in a more structured fashion by resorting to regression analysis. In a first set of regressions (referred to as "ordinary least squares [OLS] regressions"), we investigate a simple linear relationship between the labor market trends for the young (prime age) and that of the old. The estimated relationship is of the type

$$
Y_{t}=\gamma+\theta V_{t}+\beta X_{t}+\varepsilon_{t},
$$

where $Y_{t}$ represents either the unemployment rate or the employment rate of the young, and $V_{t}$ represents either the labor force participation or the employment rate of the old. In a different specification, we also model the percentage of young individuals in education.

The covariates are GDP, a dummy for the change in compulsory education age, the median wage, the contractual wage (variation only over time), and the percentage of people in school. Apart from GDP, which is derived from the ISTAT Yearly Statistical Bulletin, all other series are derived from the SHIW data.

Results are shown in tables 6.2,6.3, and 6.4. Table 6A.2 in the appendix also shows the results with the full set of covariates. We consider both a specification with the pooled data (table 6.2) and one where we allow for gender variation and make use of a "male" dummy. This is quite relevant for Italy, as the graphs on unemployment and labor force participation rates show substantial welfare variation. There are four specifications for each regression: one is in levels, while the others experiment with different lag structures. We also consider one specification with no other covariates besides the labor force participation, one with a full set of covariates (including median wage, contractual wage, GDP per capita, etc.), and one where we select only a subset of covariates (GDP per capita, GDP growth, and the share of GDP produced by the industrial sector). ${ }^{15}$

All specifications that relate the unemployment rate (or the employment rate) of the young to the labor force participation of the older workers confirm the descriptive evidence that they tend to move in a procyclical fashion; that is, when the labor force participation of the old goes up, the employment rate of the young also increases (unemployment decreases). These estimates are also significant and robust to the inclusion of covariates. As for the young people in school, we find mixed evidence: for the level specification, an increase in labor force participation of the old is negatively related to the trend in school attendance. However, this result is usually reversed in the regression with five-year differences, suggesting that there might be a long wave in this relationship. Our view is that this result is dominated by the underlying increasing trend in schooling, which is little sensitive to business

15. It should be noted that in Italy, there is no such thing as a "minimum wage" going back for the entire time period. This is mainly because contracts envisage only a minimum contractual wage at industry level. 


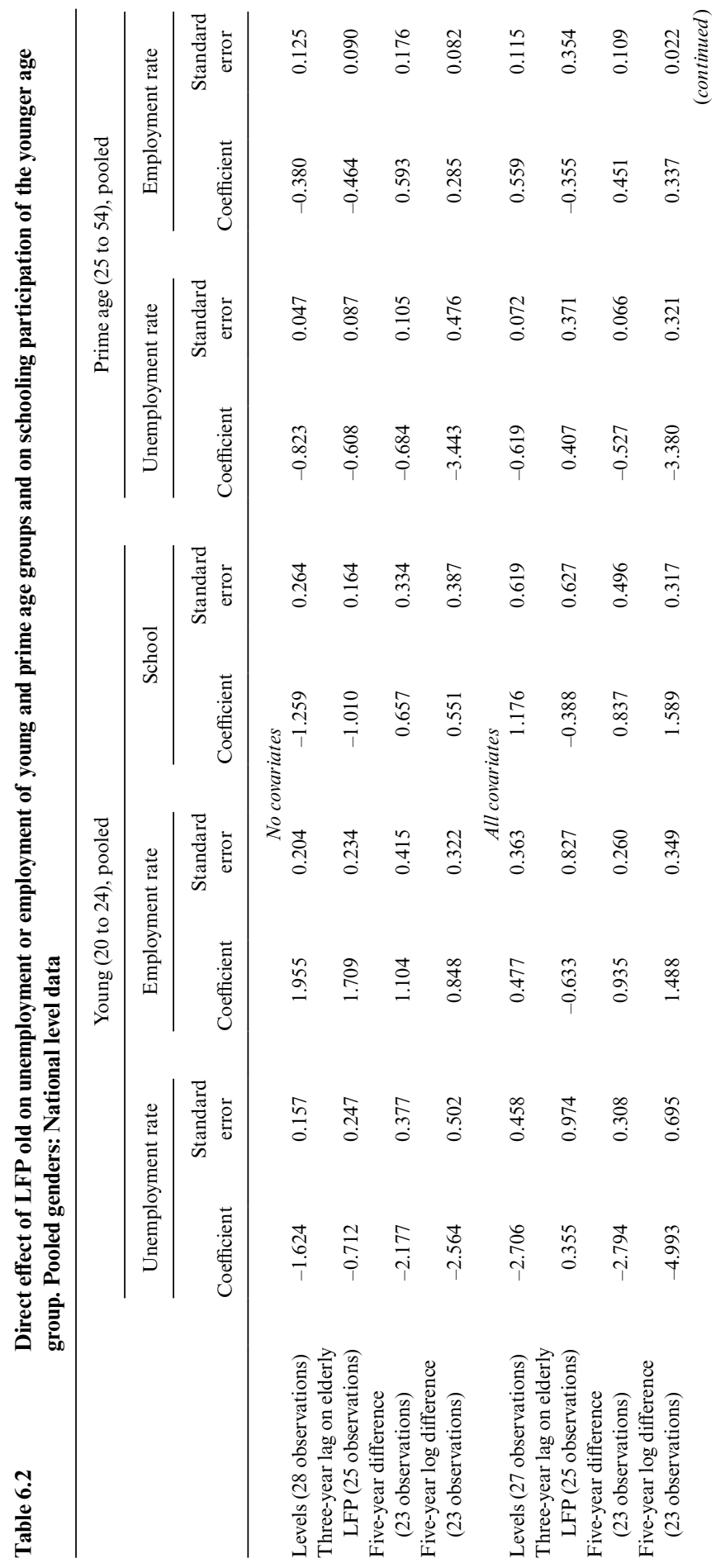




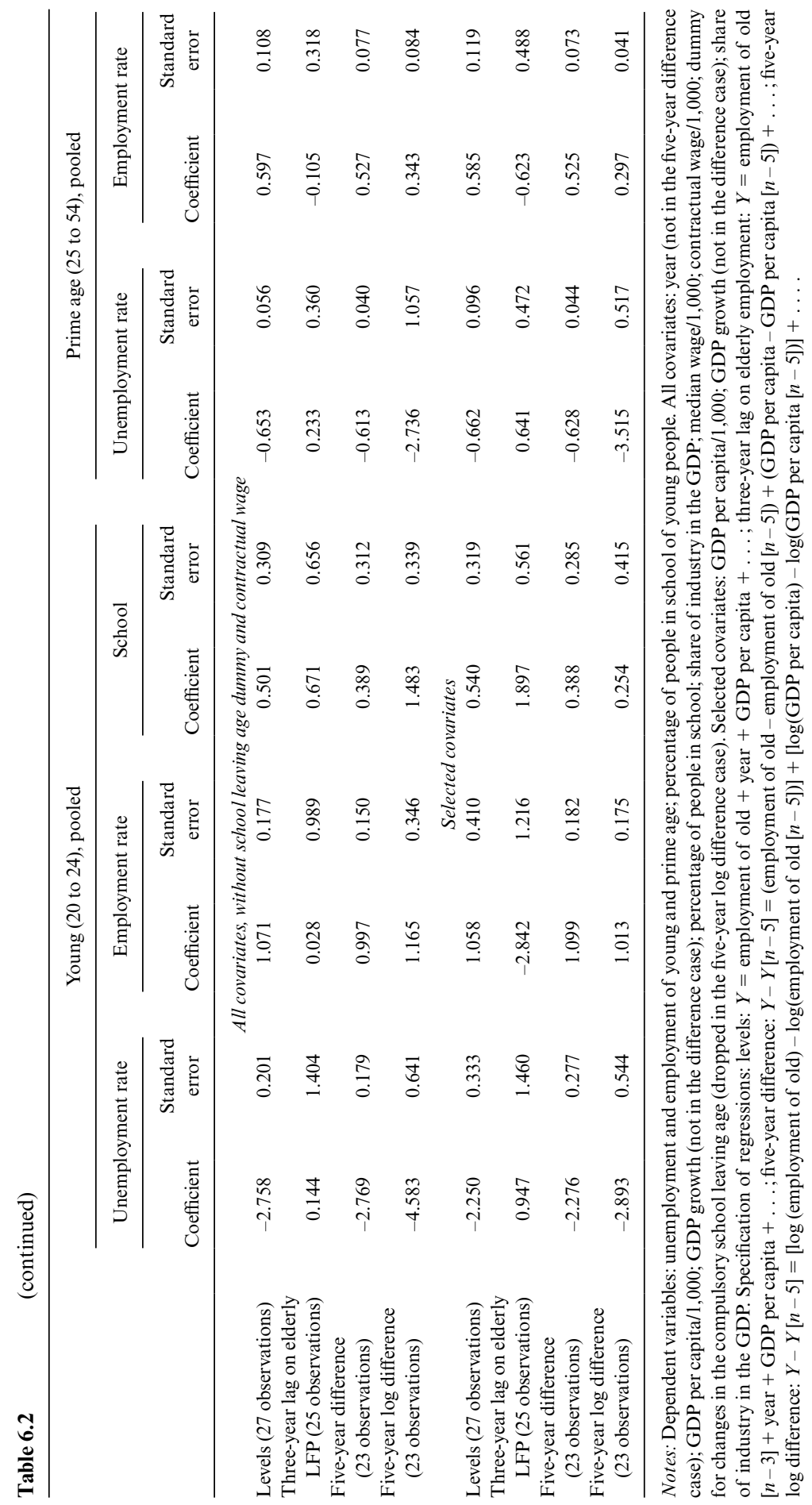




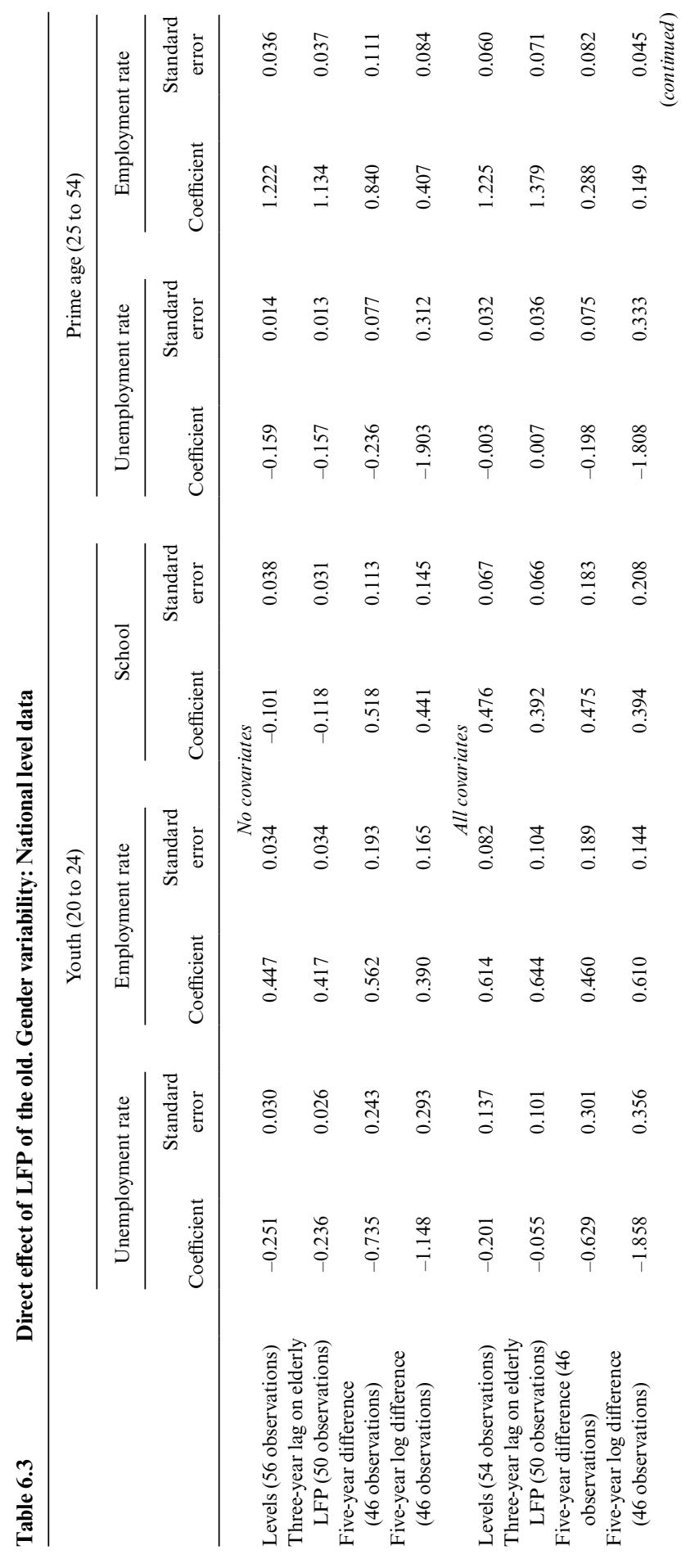




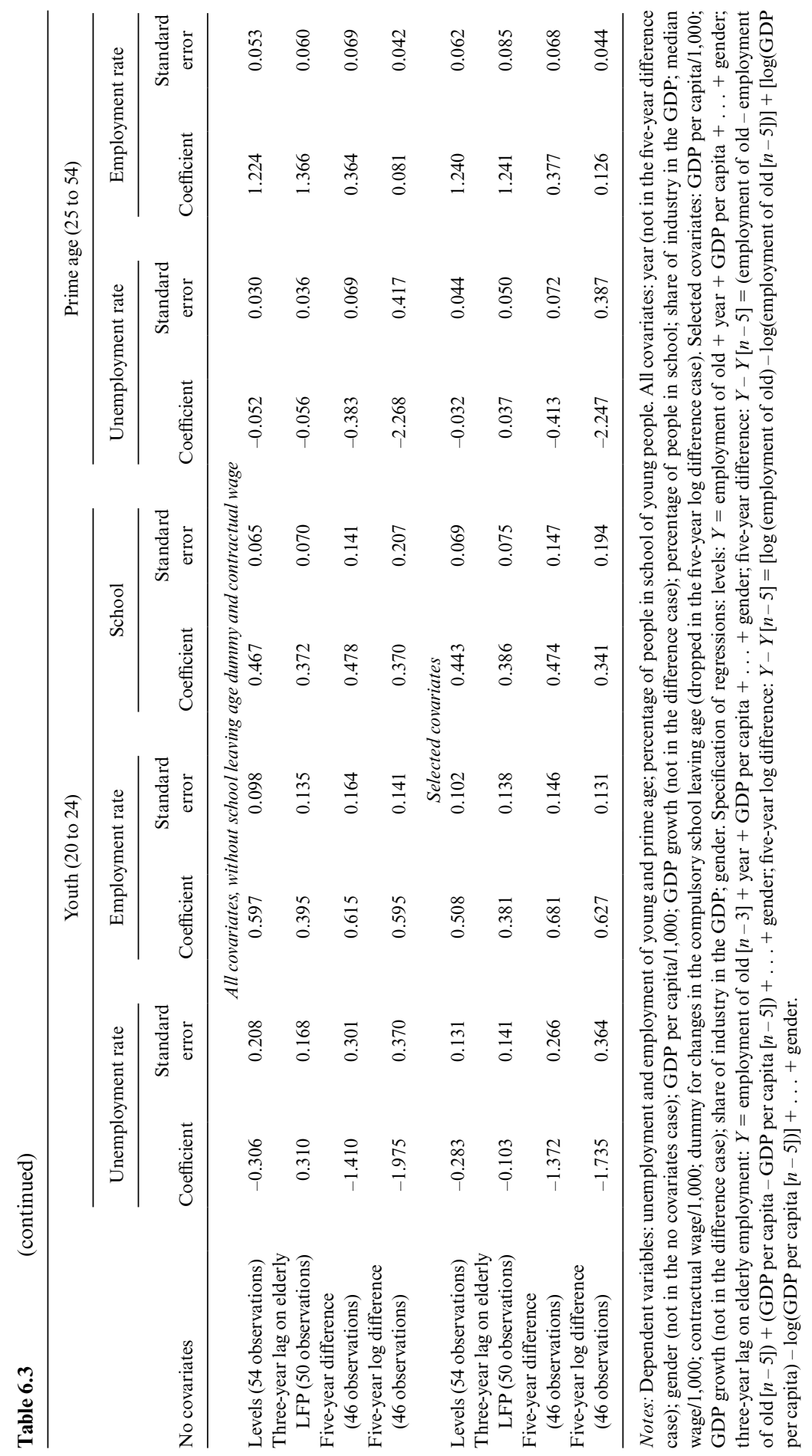




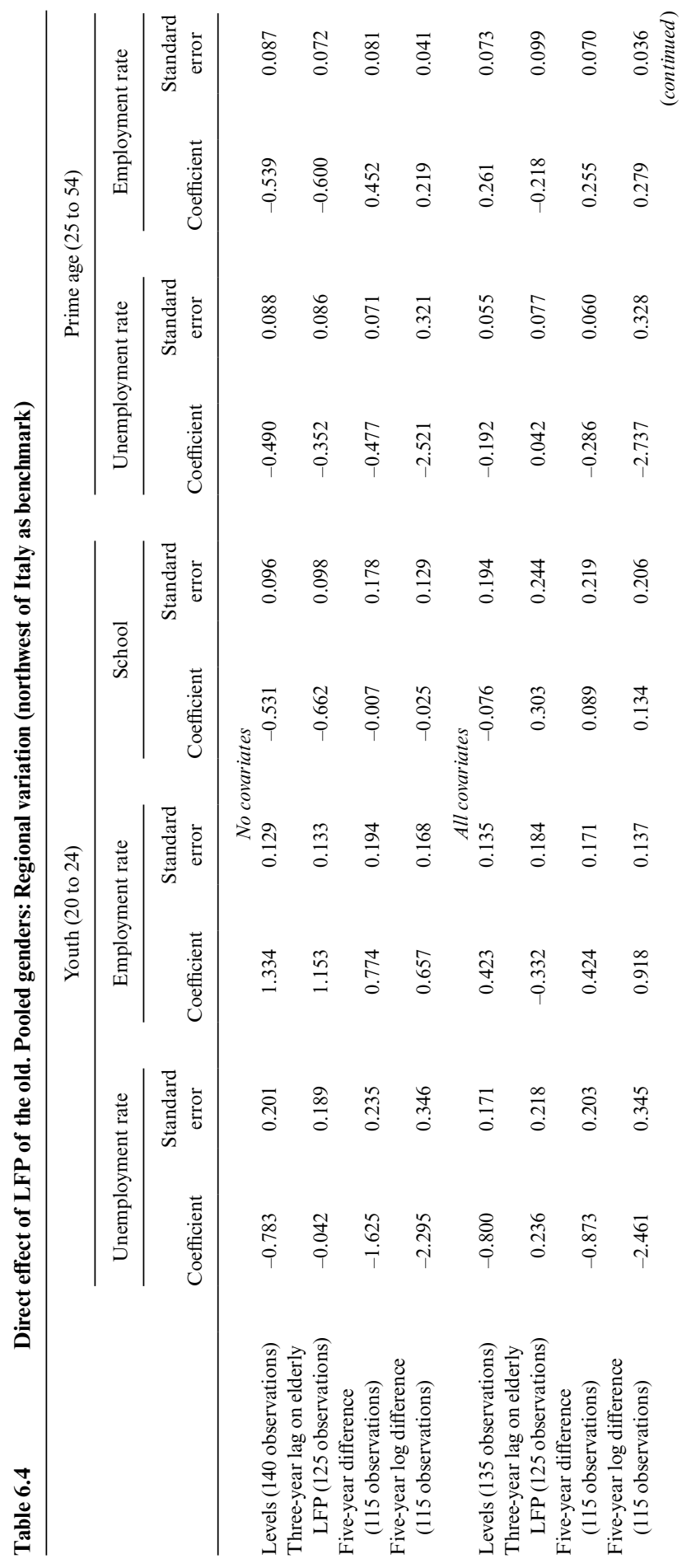




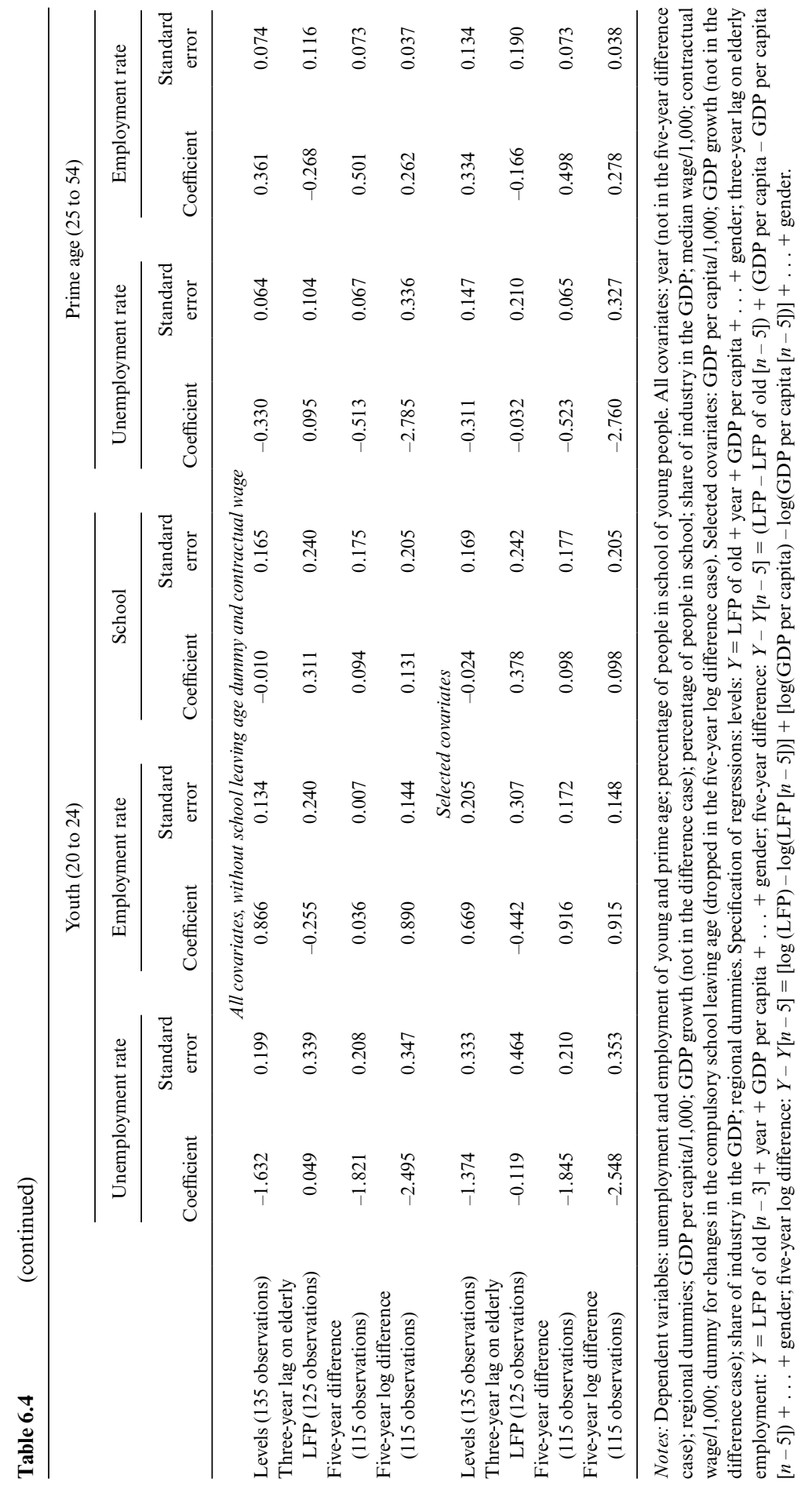


cycle variations. Interestingly enough, when we consider the employment (unemployment) of prime age workers, we find a mostly procyclical pattern: employment of prime age workers and labor force participation of the old move together. We run a simple "causality" test by looking at the impulse response functions of the unemployment rate of the young and the activity rate of the old in response to a one-time change in GDP per capita. Results are shown in the appendix (figures 6A.5 and 6A.6): the unemployment rate of the young is much more reactive to GDP changes, but this effect is not precisely estimated. One can see that both series respond to GDP in a procyclical fashion. In particular, the response of the unemployment rate is leading that of the activity rate, but the impulse response function clearly suggests that GDP is the main driver. These results are also robust to the introduction of gender variability (table 6.3) and regional variability (table 6.4). Overall, the time series of employment and unemployment of the young do not seem to be directly affected by the labor force participation rate of the old; the "young in, old out" paradigm is contradicted by the data.

As we argued, there are potential endogeneity problems in relating the unemployment rate of the young directly to the labor force participation of the old. In order to overcome these problems, we also consider a set of specifications where the main explanatory variables are the incentive variables. Results are presented in table 6.5.

Table 6.5 contains different cases:

1. The first case is obtained by choosing different levels of the $\alpha$ parameter in (3). This can take value zero (effectively focusing on the incentive variable $W$ only) or value 1.5 , which is our preferred specification. Finally, it can take the value emerging from the regression methodology (albeit with the wrong sign and not significant).

2. The second case is obtained by including liquidity constraints in the estimation of the index $I$.

3. The third case varies with the use of covariates.

4. The fourth case depends on the lag/differencing structure, starting, as usual, from the specification in levels.

Results are very robust to the different variants just described. By focusing attention on the case where $\alpha=1.5$ and where there are no liquidity constraints, one can see that a larger inducement to retire has a positive and significant effect on the unemployment rate of the young (negative on the employment rate). Hence, incentives directed to the elderly have no beneficial effect on the unemployment rate of the younger generations. A similar lesson is drawn when the dependent variable is the schooling rate of the young. The only cases where some of the effect is lost is when we resort to five-year differences (which reduces the sample size). On the other hand, incentives to retire have a strong and positive effect on exits from the labor 


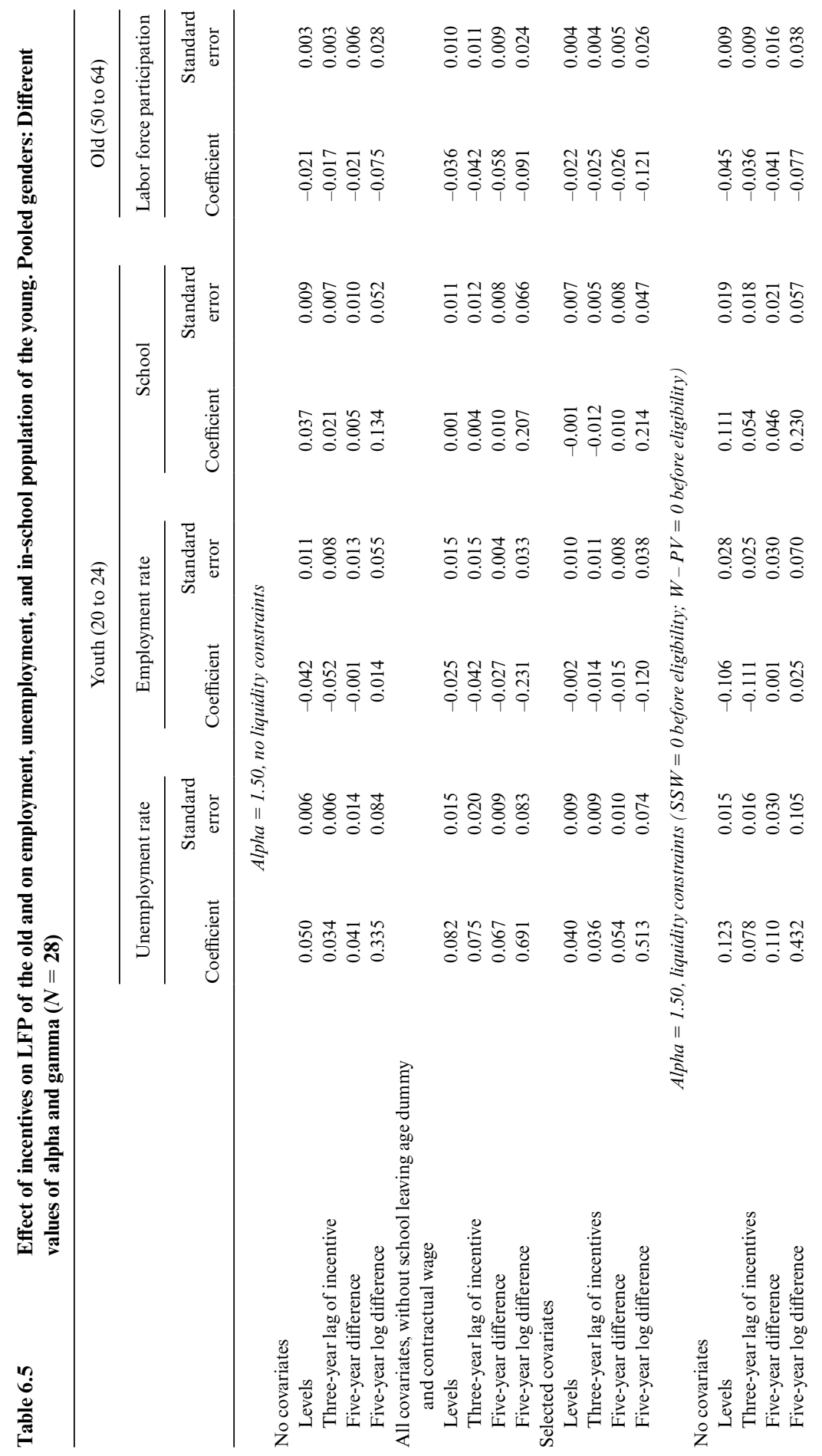




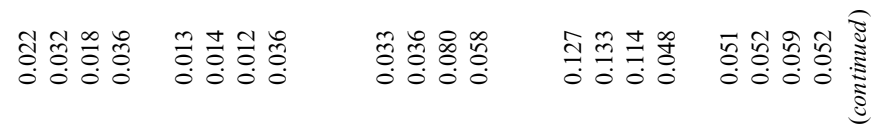

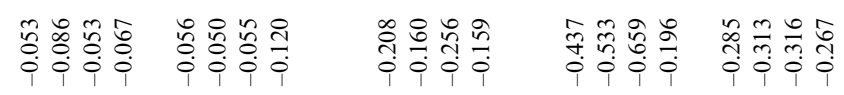

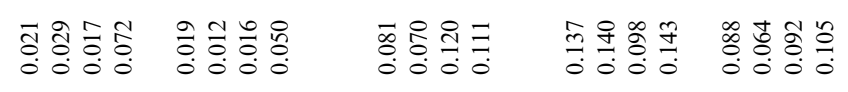

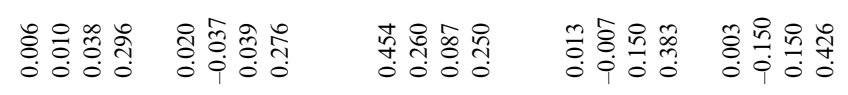

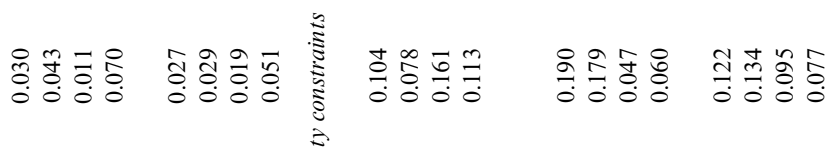

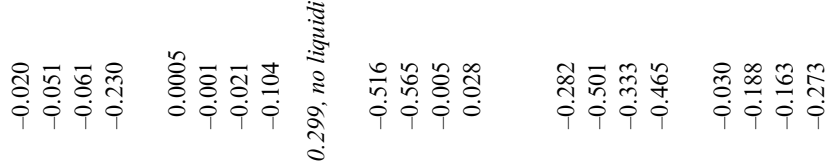

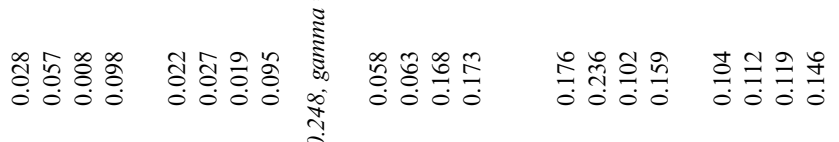

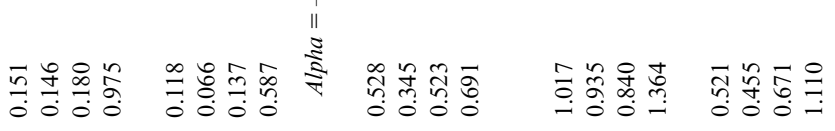
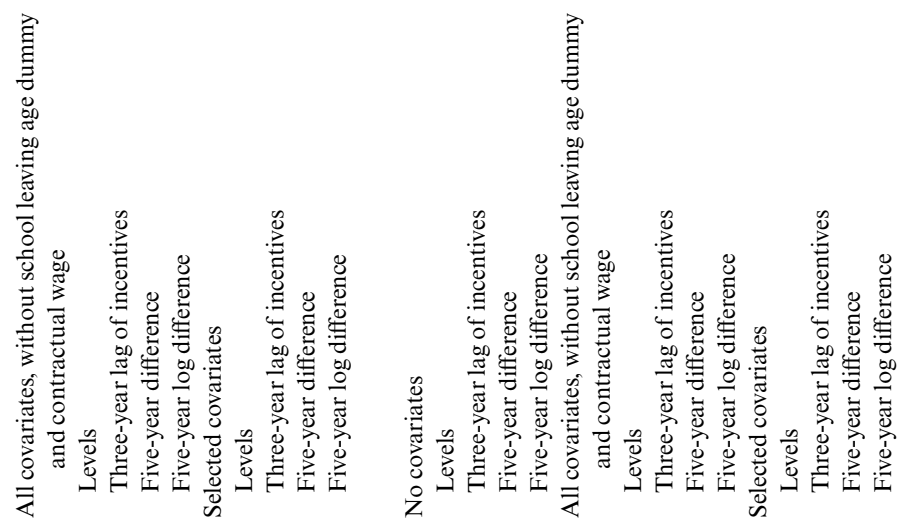


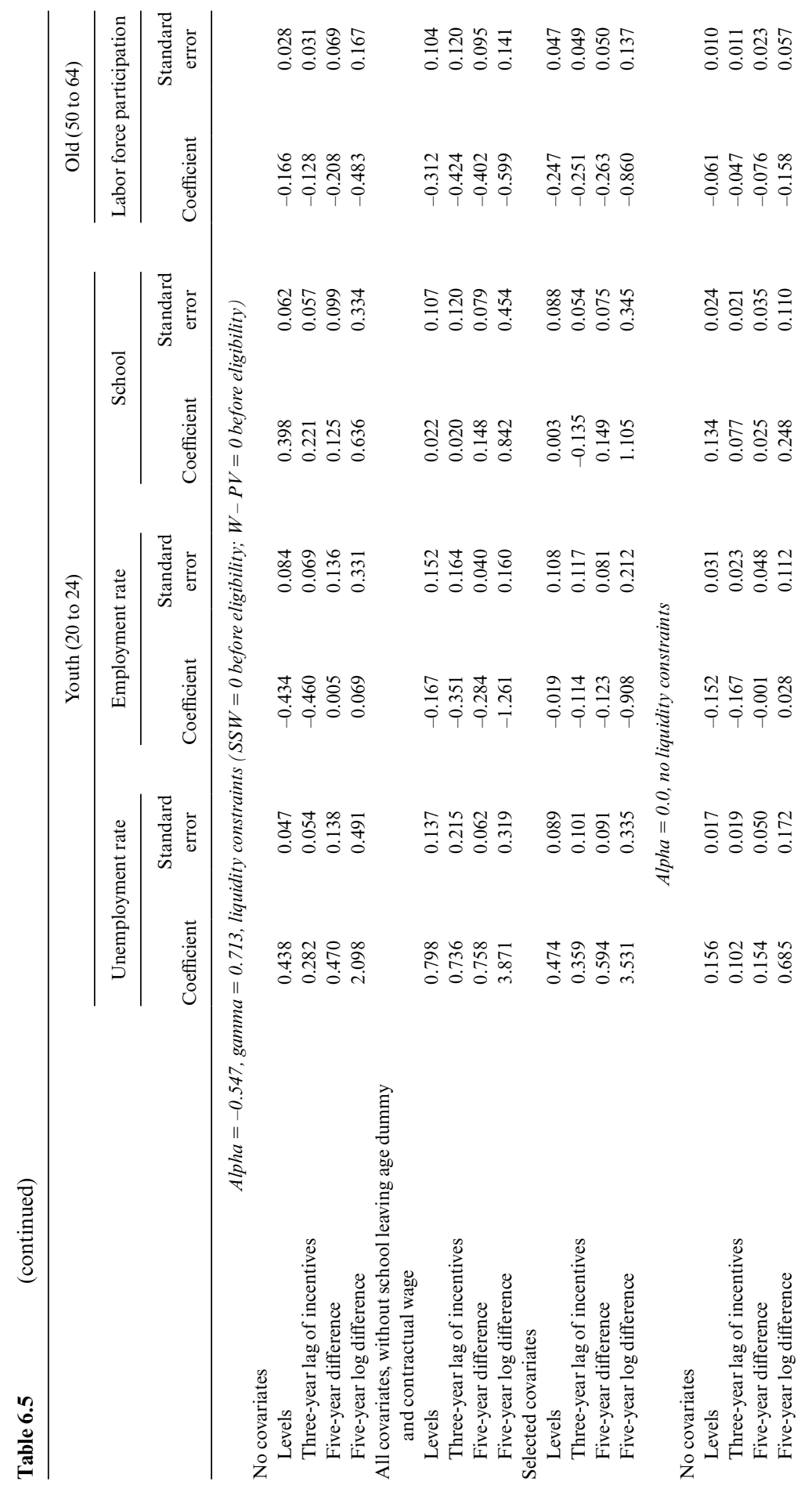




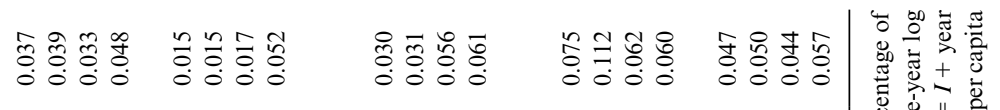

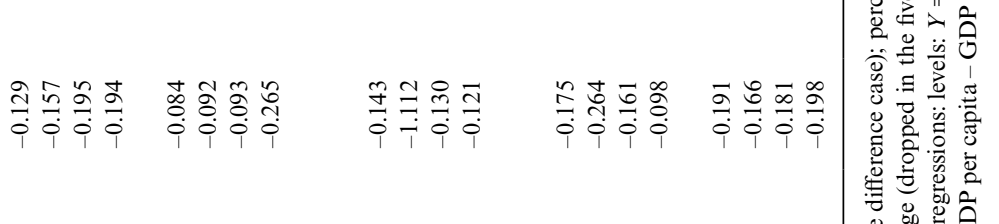

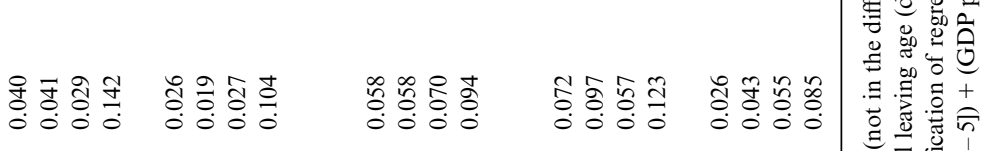

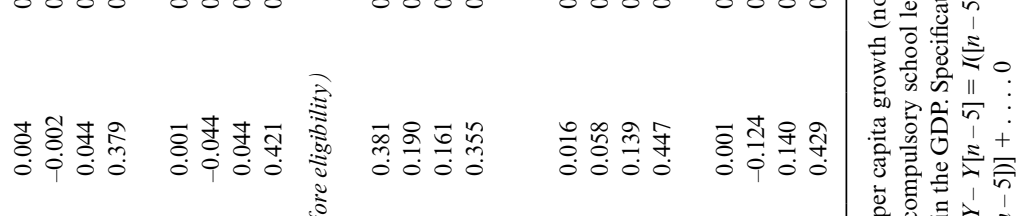

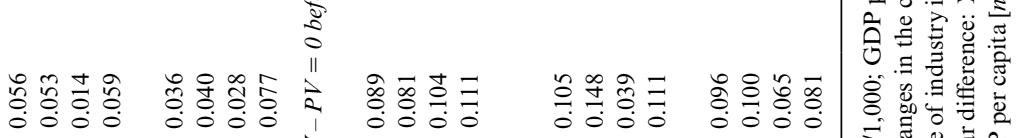

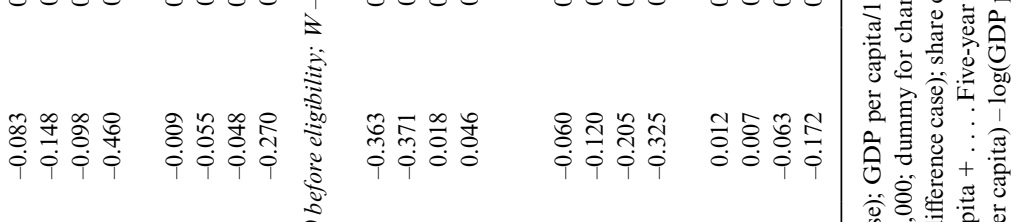

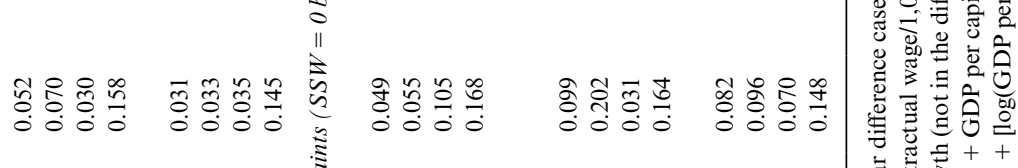

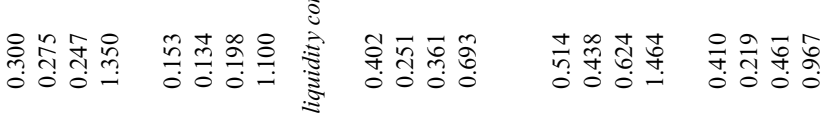


force of the elderly, as the labor force participation of the older groups shows a negative and significant coefficient.

\subsection{Conclusions}

Italy is a country characterized by high rates of unemployment, particularly for the younger generations. The generosity of the pension system prior to the reforms of the 1990s has encouraged many workers to retire early, and some policymakers, particularly unions, have supported the "young in, old out" paradigm. We show that for Italy, the "lump of labor" assumption fails, and we do this through two main routes.

First we show that the direct relationship between the unemployment rate of the young (age twenty to twenty-four) and the labor force participation of the old (fifty-five to sixty-four) is procyclical; that is, higher labor force participation of the old is associated with a lower unemployment rate of the young. This correlation occurs because both are driven by the business cycle. This result is very robust to the lag structure that we impose, so it is not just an artifact of the timing of the business cycle. It does not change when we distinguish groups by gender, given the important gender differences in labor market behavior.

The second route recognizes that the previous approach may suffer from endogeneity problems. Hence, we resort to a simulated variable, "the inducement to retire," which is constructed by simulating the social security benefits accruing to the median worker, taking into account the relevant social security legislation. There are two versions of this incentive variable: one is simply the average social security wealth, and the other is an index that also includes the potential gains (losses) from postponing retirement; the latter captures elements of forward-looking behavior.

We relate the unemployment rate of the young to these incentive measures and find that a higher inducement to retire is associated with a higher unemployment rate - quite the opposite of the "young in, old out" story. The variables capturing the inducement to retire have a significant effect on the labor force participation of older workers. This effect has the expected sign (the higher the incentive, the lower labor force participation) and is very robust to different specifications, suggesting that Italian workers responded to social security incentives. 


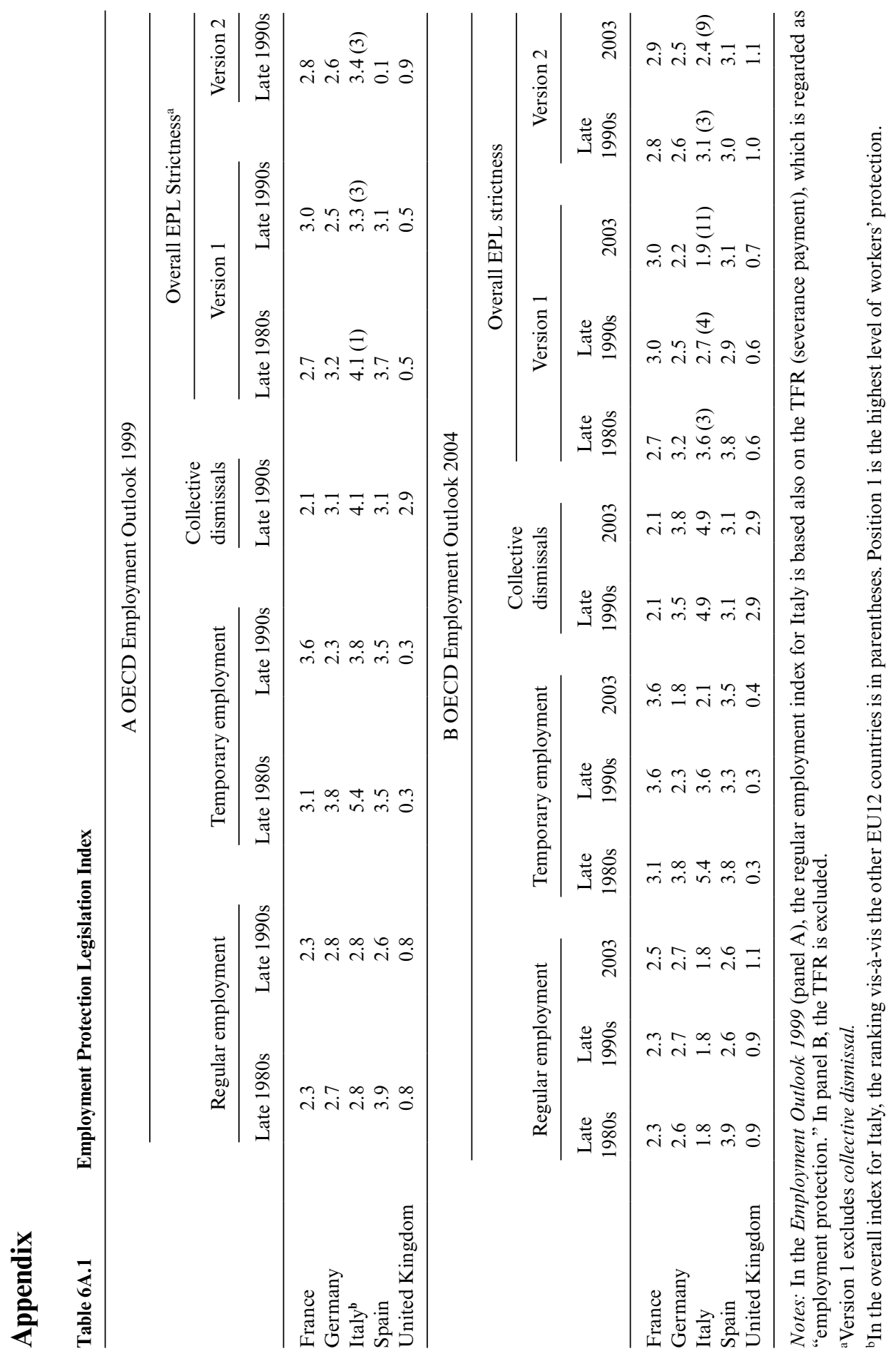




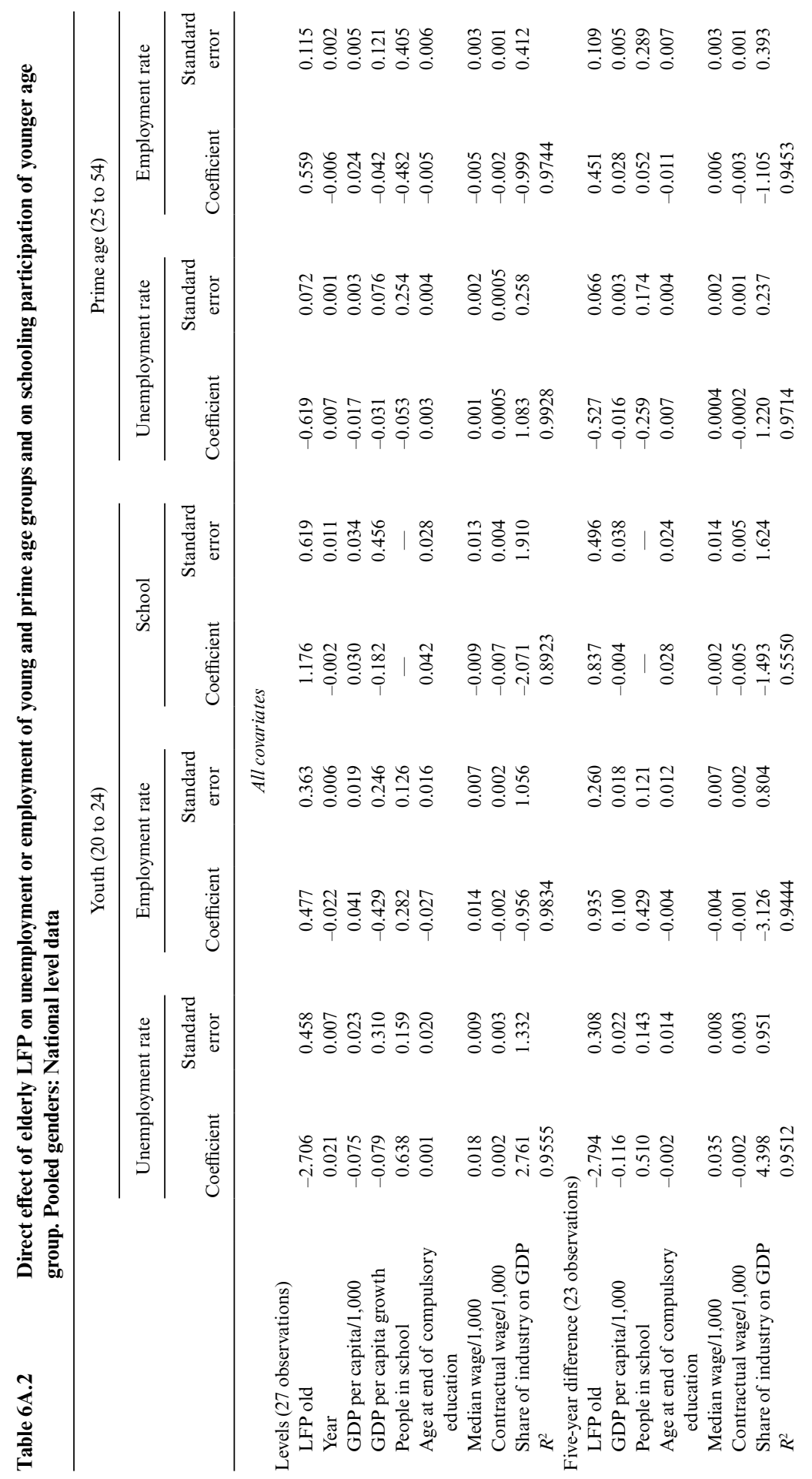




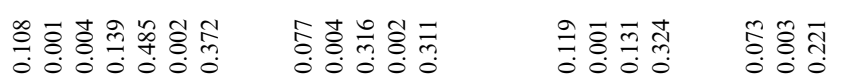

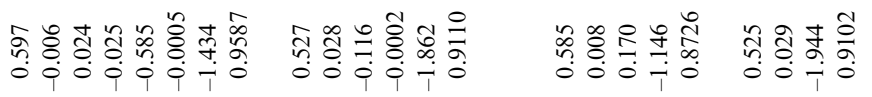

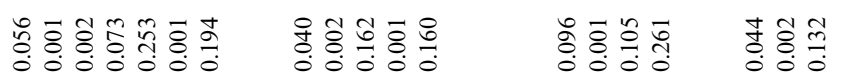

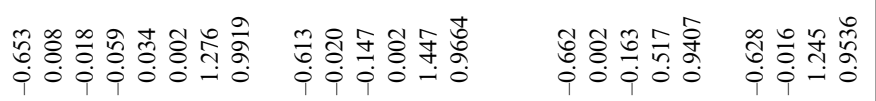

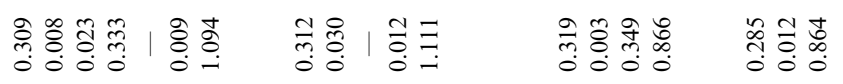

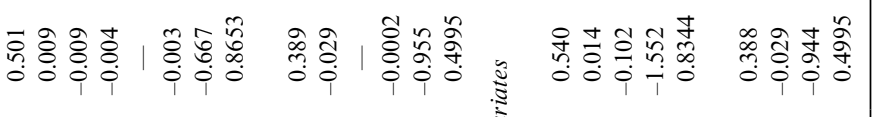

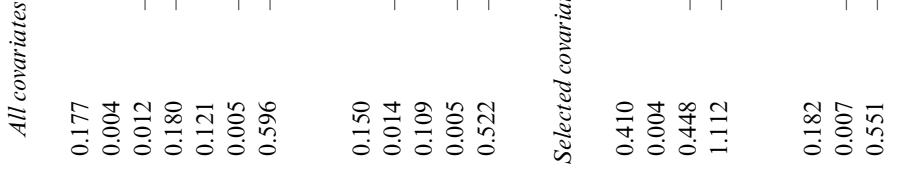

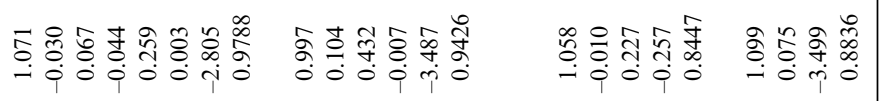

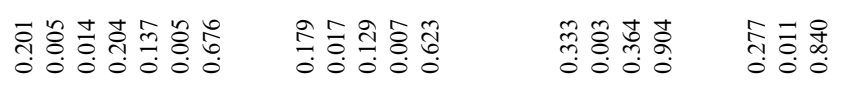

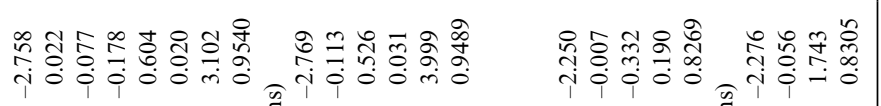

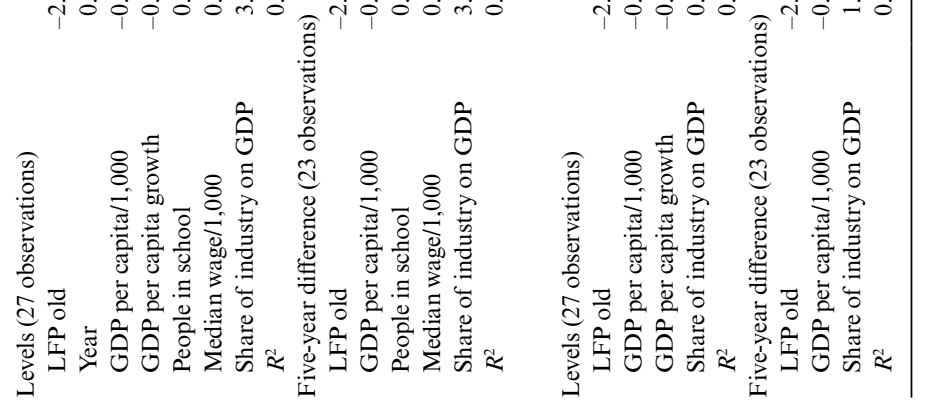




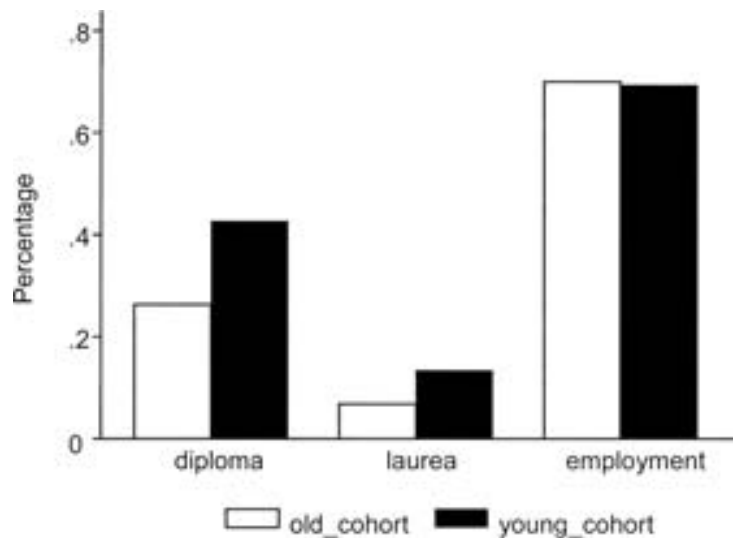

Fig. 6A.1 Prevalence of a secondary degree (diploma), university degree (laurea), or work for different cohorts

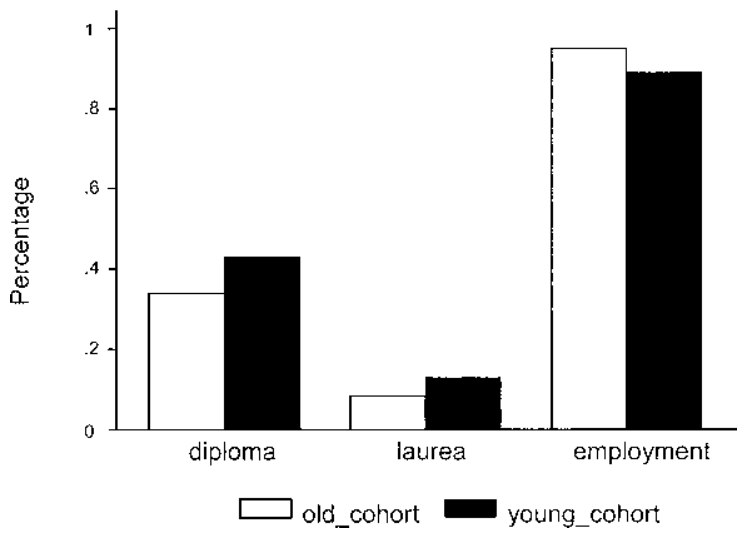

Fig. 6A.2 Prevalence of a secondary degree (diploma), university degree (laurea), or work for different cohorts: Males

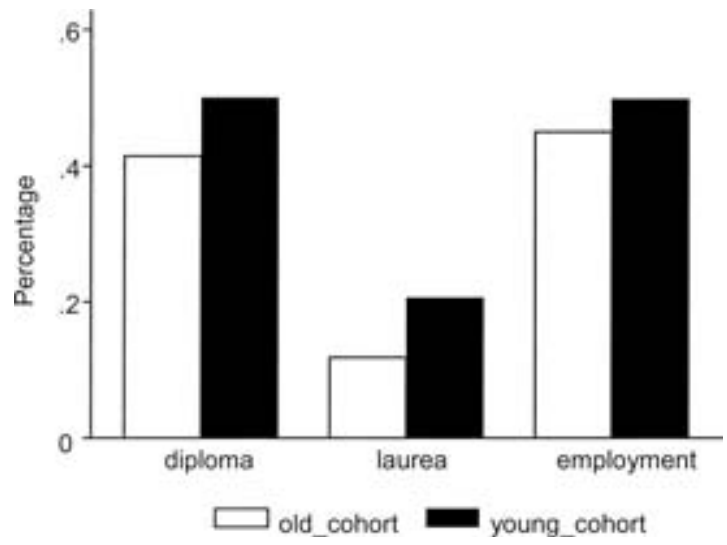

Fig. 6A.3 Prevalence of a secondary degree (diploma), university degree (laurea), or work for different cohorts: Females 


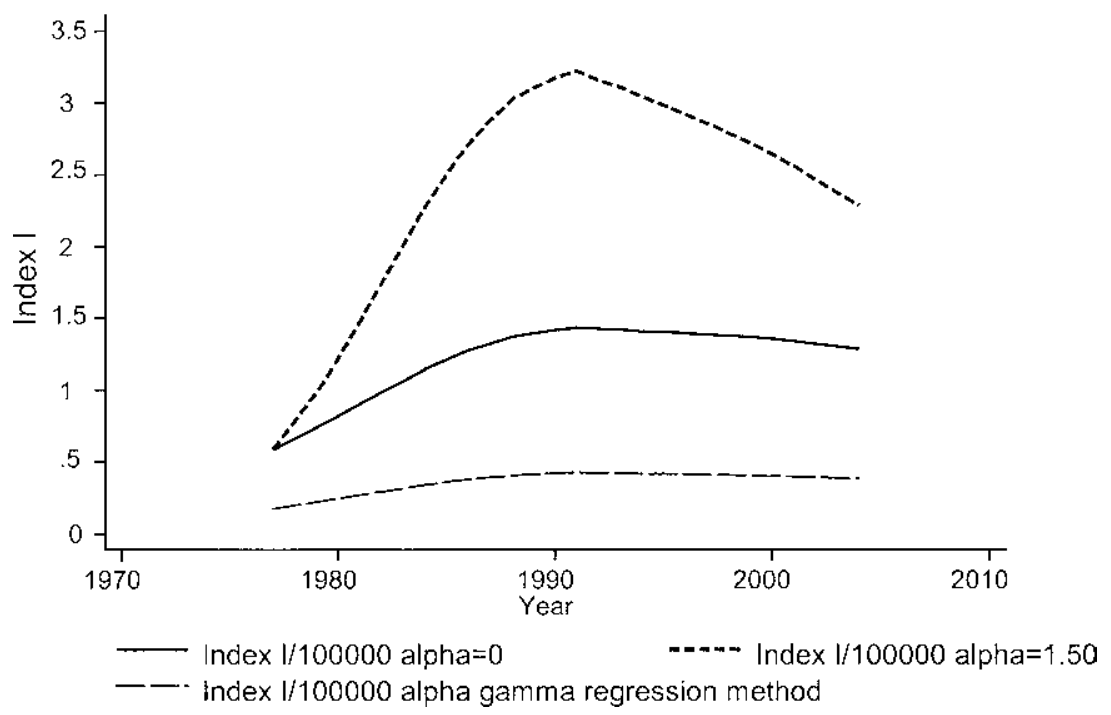

Fig. 6A.4 Index I for different values of alpha

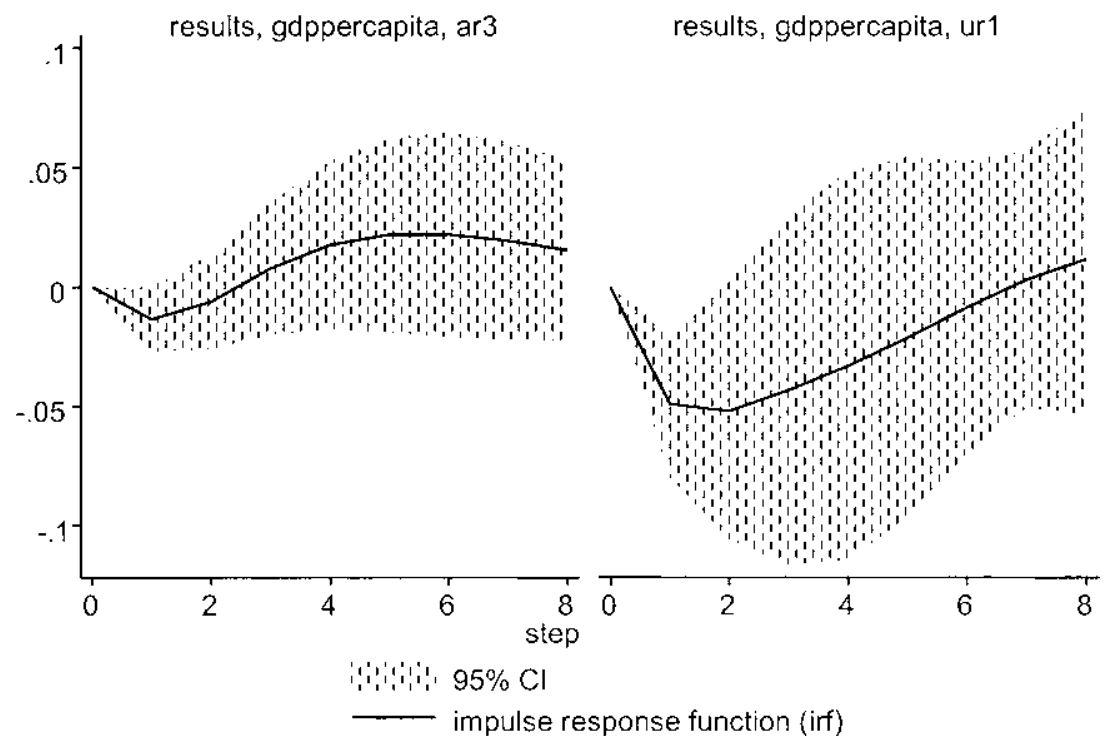

Fig. 6A.5 Impulse response function of the activity rate of the old (AR3) and the unemployment rate of the young (UR1) in response to GDP per capita 


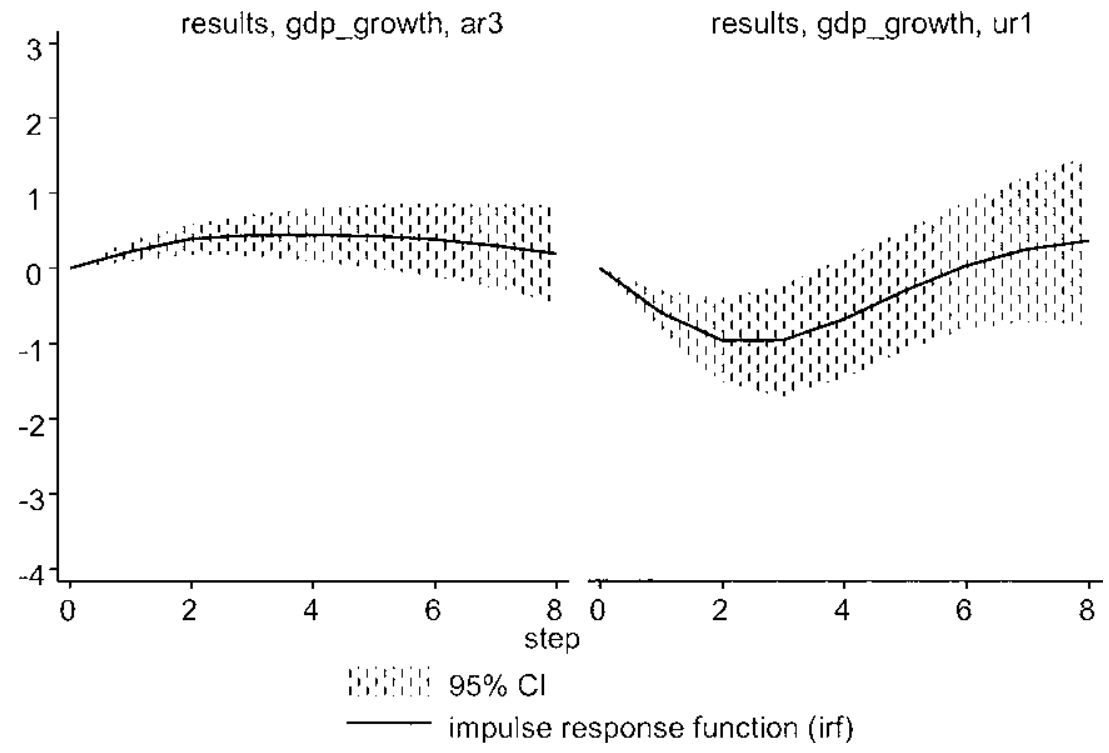

Fig. 6A.6 Impulse response function of the activity rate of the old (AR3) and unemployment rate of the young (UR1) in response to GDP growth

Notes: The impulse response function, computed after running a vector autoregression (VAR), shows the change over time of the variables UR1 (unemployment young) or AR3 (activity old) in response to a one-time impulse of the variables GDP per capita or GDP growth. This is done keeping all the other variables of the VAR constant.

\section{References}

Attanasio, O., and F. Padoa-Schioppa. 1991. Regional inequalities, migration and mismatch in Italy, 1960-1986. In Mismatch and labour mobility, ed. F. PadoaSchioppa, 237-32. Cambridge: Cambridge University Press.

Bank of Italy. 2004. Historical Database of the Survey of Italian Household Budgets, 1977-2002: Version 3.0. Rome: Bank of Italy.

Bentolila, S., and G. Bertola. 1990. How bad is eurosclerosis? Review of Economic Studies 57 (3): 381-402.

Bertola, G. 1990. Job security, employment and wages. European Economic Review 34 (4): 851-66.

1999. Microeconomic perspectives on aggregate labour markets. In Handbook of labour economics, vol. 3B, ed. O. Ashenfelter and D. Card, 2985-3028. Amsterdam: North-Holland.

Bodo, G., and P. Sestito. 1991. Le vie dello sviluppo. Bologna: Il Mulino.

Boeri, T., and P. Garibaldi. 2007. Two tier reforms of employment protection: A honeymoon effect? Economic Journal 117 (521): 357-85.

Boldrin, M., J. Dolado, J. Jimeno, and F. Peracchi. 1999. The future of pensions in Europe. Economic Policy 29:289-320.

Brugiavini, A. 1999. Social security and retirement in Italy. In Social security and 
retirement around the world, ed. J. Gruber and D. A. Wise, 181-237. Chicago: University of Chicago Press.

Brugiavini, A., and V. Galasso. 2004. The social security reform process in Italy: Where do we stand? Journal of Pension Economics and Finance 3:165-95.

Brugiavini, A., and F. Peracchi. 2003. Social security wealth and retirement decisions in Italy. Labour 17 (special issue): 79-114.

. 2004. Micro-modeling of retirement behavior in Italy. In Social security programs and retirement around the world: Micro-estimation, ed. J. Gruber and D. A. Wise, 345-98. Chicago: University of Chicago Press.

2005. The length of working lives in Europe. Journal of the European Economic Association 3:477-86.

. 2007. Fiscal implications of pension reforms in Italy. In Social security programs and retirement around the world: Fiscal implication of reforms, ed. J. Gruber and D. A. Wise, 253-94. Chicago: University of Chicago Press.

Brunello, G., C. Lupi, and P. Ordine. 2001. Widening differences in Italian regional unemployment. Labour Economics 8 (1): 103-29.

Caroleo, F. E., and F. Mazzotta. 1999. Youth unemployment and youth employment policies in Italy. ILO Employment and Training Paper no. 42. Geneva: International Labor Organization.

Contini, B. 2005. Invecchiamento e precarizzazione giovanile nell'occupazione italiana: È possibile una chiave di lettura unificata? Rivista di Politica Economica (March-April): 323-35.

Contini, B., and F. M. Rapiti. 1999. "Young in, Old Out" revisited: New patterns of employment replacement in the Italian economy. International Review of Applied Economics 13:395-415.

Franco, D. 2002. Italy: A never-ending pension reform. In Social Security pension reform in Europe, ed. M. Feldstein and H. Siebert, 211-62. Chicago: University of Chicago Press.

Manacorda, M., and B. Petrongolo. 2006. Regional mismatch and unemployment: Theory and evidence from Italy, 1977-1998. Journal of Population Economies 19:137-62.

Organization for Economic Cooperation and Development (OECD). 1999. Employment outlook. Paris: OECD.

Rossi, N., A. Sorgato, and G. Toniolo. 1993. I conti economici italiani: Una ricostruzione statistica, 1890-1990. Rivista di Storia Economica, 2nd ser., 10 (1993):1-47. 